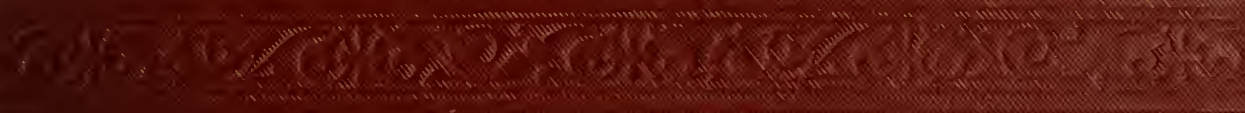

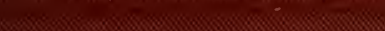

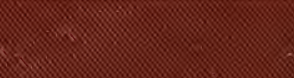

$\cdots \cdots$

$\cdots \cdots$
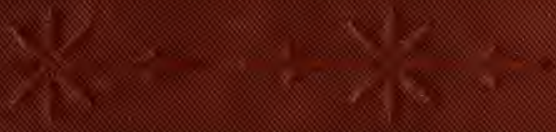

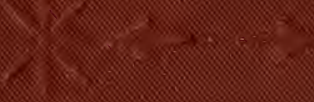
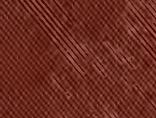

$\cdots$
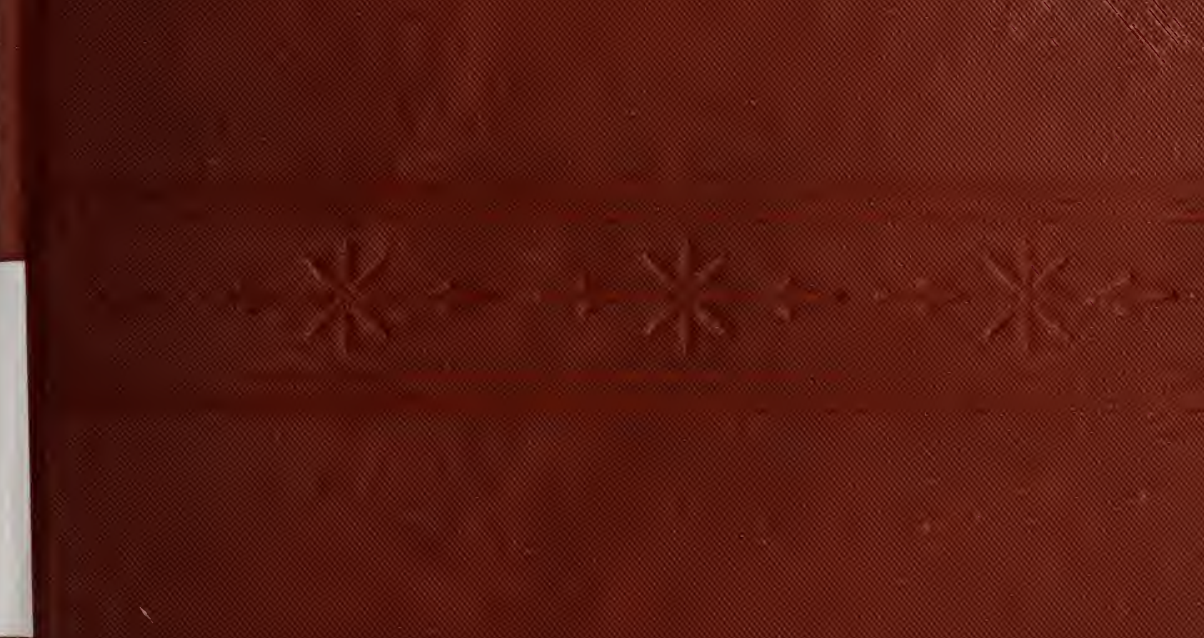

Nos 


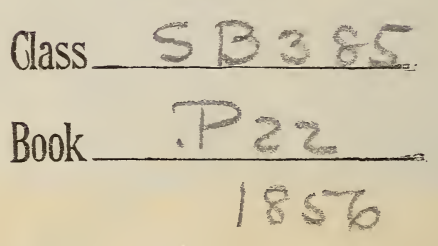

U. N. I A I LLI UNFIUE.

$\mathcal{N} o$ Class

Case Shelf.

(a) 
in 




\section{COMPLETE MANUAL}

FOR THE

\section{Cenltivation of the Stratuberty;}

WITH $\mathbb{A}$

\section{DESCRIPTION OF THE BEST VARIETIES.}

AISO, NOTICES OF THE

RASPBERPY, BLACKBERPY, CRANBERRY, CURRANT, GOOSEBERRY, AYD GRAPE;

WITH DIRECTIONS POR THEIR CULTIVATION, AND THE SELECTTON OF THE BEST VARIETIES.

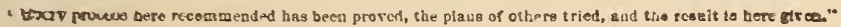

NEW AYU REVISED EDITION.

\section{BY R.G. P. PR DEE.}

TITE A VALUABLE APPENDIX,

COTTAEINO TER OBSERVATIONS AND EXPERIENCE ON BOME OT THR MOET SUCCESBECL CULTIYATORS OF THESB FRUTY IN OUR COCNTRY.

$$
36,1 / 2, \cdots
$$

ORANGE JUDD \& COMPANY. 245 BROADW A

$$
\text { [1856] }
$$


$s^{3^{3}} \frac{8^{2}}{85^{2}}$

Eirtored according to Act of Congress, in the year 1856, by

C M SEXTON \& CO.

Ls the Clergies Office of the District Court of the United States, for the Southern Distress? New York.

69 trendier IIUL

Dat. Qr at Lit,

Apr lola 


\section{Contents.}

PAGB

Preface to the Tenth Revised Edition...............

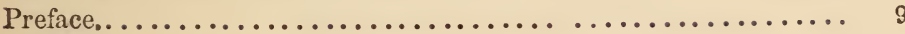

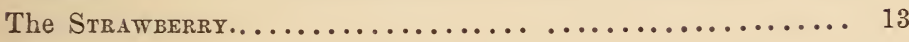

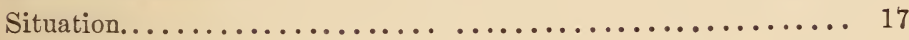

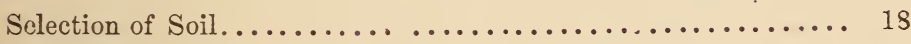

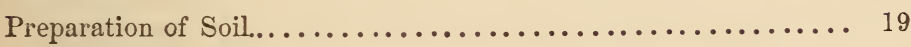

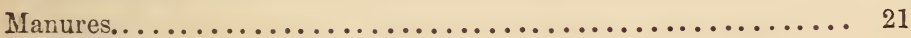

Transplanting (Time and Manner of)............... 25

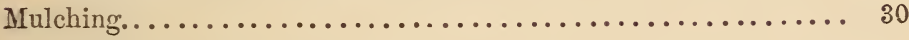

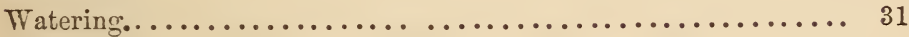

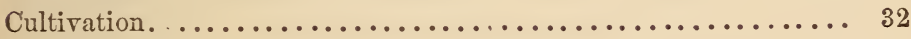

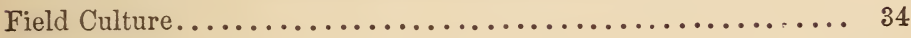

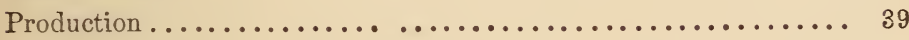

Renewal of Beds........................... 42

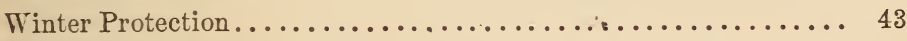

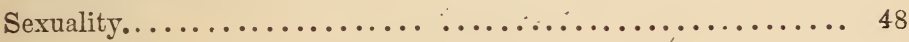

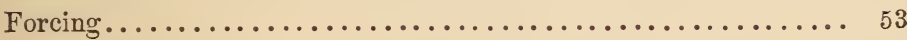

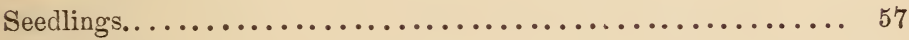

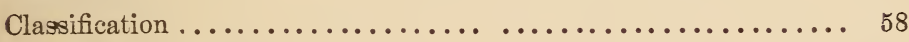

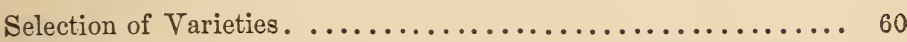

McAvoy's Superior-Hovey's Seedling-Monroe ScarletBurr's New Pine-Longworth's Prolific-Walker's Seedling-IIcAvoy's Extra Red-Jenney's Seedling-Large Early Scarlet-Crimson Cone-Iowa-Genesee Seedling-Willey -Princess Alice Maud-Boston Pine-Black Prince-Swainstone Seedling-Myatt's British Queen-Large White Bicton Pine-Barr's New White-Prolific Hautboy. 
Analysis of the Strawberry Fruit and Plant............ 79

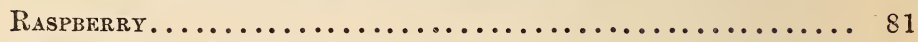

Fastolf-Franconi-Red and Yellow Antwerp-Knevett's Giant -Large-fruited Monthly-Ohio Ever-bearing-Orange.

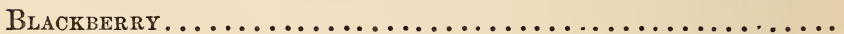

White-Improved High Bush-New Rochelle.

Cranberry................................ 9

Black.

Currant.

Black Naples-White and Red Dutch-White and Red Grape -Cherry-May Victoria-Knight's Sweet Red-Largest White Provence-La Versailles.

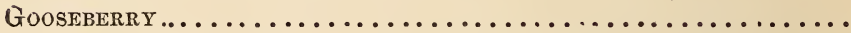

Crompton's Sheba Queen-Woodward's Whitesmith-Roaring

Lion-Crown Bob-Houghton's Seedling, \&c.

Isabella-Catawba-Clinton-Concord--Diana-Black Madeira -Delaware-Anna-Iowa, \&c.

\section{APPENDIX.}

Peabody on Ever-bearing Strawberries................ 111

Peabody's Letter to R. G. Pardee................... 111

Huntsman's Experiments........................ 121

Lungworth's Letter to R. G. Pardee................... 124

Report of Cincinnati Horticultural Society............. 126

Parry's Directions for Cultivation of Strawberry..... . . . . 129

Mead's " " $"$ " $\ldots \ldots \ldots \ldots .140$

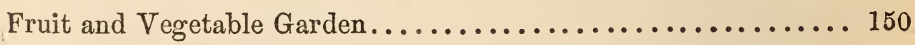




\section{PREFACE}

TO THE TENTH EDITION.

Is preparing the present edition for the press, I have concluded to revise and modify erery expression, in the light of the past experiences and observation of the Horticultural world up to the present time.

Great changes have been brought about in the Strawberry by the introduction of new varieties, all requiring somewhat different treatment.

For instance, Wilson's Seedling was introduced a few years ago, and it is not too much to say, that it will, under the best treatment, produce twice or three times as much fruit as any known variety of the Strawberry would do when this work was originally prepared. Since then, other similar varieties, enormous bearers, have been introduced, and they consequently require richer soil and higher culture. This work never advocated poor soil or poor culture as some have erroneously supposed, but it simply cautioned against excessive stimulation-to grow leaves and plants instead of fruit.

There is still much complaint of many failures in the cultivation of the Strawberry. Some get one or two crops and then run out, and they give up in despair, when the fault is all their own. They are not exact and accurate enough in their treatment of their plants, and 
the most common causes of failure seem to be the following, viz:-

1. Allowing two or more varieties to grow and mix in the same bed. This in two years will prove fatal if allowed to run. Permit but one kind in a bed.

2. Allowing the plants to grow too compactly. If you keep every single plant ten or twelve inches distant from every other, it will remedy this evil.

3. Keep clear of weeds, without maiming the plants by chopping off the little fibrous roots. Do not hill up the plants, but give level culture; use the spading fork and mulch well.

At the head of the new proved varieties I would certainly place Wilson's Seedling. In Ohio, last June, I was told that Wilson's was twice as productive as any other variety. Illinois and Indiana told me the same story; while strawberry growers of Wisconsin insisted that it would bear four times as much as any other kind. I have never seen so productive a berry. It is large in size, brisk acid, but good flavor when fully ripe, and hardy.

Triomphe de Gand is an excellent Belgian variety, and has become a great favorite. It is sweeter, pleasanter flavor than Wilson's, very large, often coxcomb shape, and is very productive.

Mr. Fuller's Seedlings, the Brooklyn Scarlet, Colonel Ellsworth and the Monitor, generously sent out by the New York Tribune Association, are large, fine productive varieties that promise well.

The same may be said of Mr. Burgess's Seedling, Gen. eral Scott and others. 
Russell's Seedling originated (with a gentleman of that name) in a garden which I formerly owned in Seneca Falls. It is very large, productive, good flavor and promises well.

Boynton's Nero Seedling, "the Agriculturist strawberry," recently sent out by the enterprising proprietor of the American Agriculturist, is of enormous size, and one of the handsomest berries I have yet seen. The flavor is good and seems to be productive. It certainly promises well.

In the descriptions of Strawberries in the body of this work, we would now discard altogether, as being superseded by other kinds, the following varieties, viz:Monroe Scarlet, McAroy's Extra Red, Iowa, Genesee Seedling and Willey.

Some of the other varieties are retained only on account of some single desirable quality for amateurs. A good list at the present time would be:

Wilson's Seedlings, Triomphe de Gand, Longworth's Prolific, Hooker's Seedling, Hovey's, and we hope some of Fuller's, Burgess's, Russell's and Boynton's Seedlings.

The Fruits of America are so fine as to clain more time, more care, more intelligent observation, and personal attention than has hitherto been given to them, for in no other way can old mother eartb be made to yield a more sure and ample reward. We shall do weil always to remember, as quoted by Mr. Downing, that "Fine fruit is the flower of commodities."

New York, January, 1865.

THE AUTHOR. 


\section{PREFACE.}

THIs work has been prepared for the press, in the belief that it was wanted by the public.

The author has, in a direct, plain manner, simply given his own experience.

Every process here recommended has been proved; the plans of others tried, and the result is here given.

Every variety of fruit here introduced-except the Lawton Blackberry and two or three small, unimportant fruits-has been planted, fertilized, watered, cultivated, and carefully watched daily for months, and in most cases, for years; so that it is not mere theory, or seeond-hand information from amateurs or gardeners, however superior, that is here recorded.

With proper cultivation, a large crop of strawberries may be expected every year with as much certainty as a crop of corn, and in fact, more so, for our directions embrace a protection from drought, which so frequently lessens the corn crop.

It will be readily seen that the author has not followed the rules and order usually observed in treating 
upon these subjects; but has aimed to say what he means, in a condensed, business-like way, so that he may be understood by the mass of readers.

It does not by any means follow, that every one who reads this book will at once raise the largest and most luscious strawberries and other choice fruits here named, in the greatest abundance. Few persons are thorough enough to do any thing well at first.

Place a new recipe for making premium bread in the hands of six cooks, and it would be quite remarkable if half of them were so particular as to make good bread on the first trial. Some little thing which seems to the unskilled to be unimportant, may in fact be essentiàt.

It is pleasant to know that so many intellize eit cultivators are now turning their attention to the production of these fine fruits, and we may reasonalily expect much additional light will be thrown upon some points, which shall be included in subsequent editions of this work.

The writer is happy to acknowledge his obligations to a large number of cultivators of these fruits during the last few years, for valuable suggestions which he has become so familiar with in practice, that doubtless even their precise language has been sometimes unconsciously woven into the text of this worls. If it were possible, he would be more specific in his acknowledg 
ments, for it is pleasant to speak of such autnors as $A$. J. Downing, Jıhn J. Thomas, P. Barry, C. M. Hovey, and latterly F. R. Elliott, who has politely assented to our use of some of the accurate drawings of fruits from his new Fruit Book and Guide.

Our Appendix embraces much valuable original as well as selected matter, which will place before our readers the views of others, beside our own, and in some points diverse, and which will enable them to exercise their own intelligent judgment, and we hope lead to successful prastice.

THE AUTHOR. 


\section{PREFACE'}

\section{TO THESIXE EDITION。}

AFTER two years more of experience, observation and intercourse with intelligent cultivators, the author in review, can only re-affirm all the specific directions here given for the successful cultivation of the straw. berry.

Considerable progress can be reported, from the additional light thrown on the question of the best new varieties.

Three new varieties claim especial favor at the hands of the public, viz., Wilson's Seedling of Albany, Hooker's Seedling of Rochester, and Jenny Lind from near Bcston. All are staminates, and all are believed to possess some special excellence. The first named, Wilson's, seems to surpass all pistillate varieties in productiveness, thus interfering with long• established theories on that subject. We counted on one plant, one year old, on the tables of the New York Horticultural Society, 260 berries! and on several plants in the garden 160 to 200 berries! many of which were of large size-and this on single plants, not stools of plants. The second, Hooker's, is very large, very productive and of exquisite flavor, rival. ing Burr's New Pine in this regard. The third, Jenny Lind, promises to supercede Large Early Scarlet in size, productiveness, and as an impregnator to the pistillate varieties.

Hovey's Seedling, Longworth's Prolific, and Walker's Seedling, retain their favorable position in the public favor. The above list comprises, we think, a list of the best six varieties, and it is somewhat remarkable 
that all but Hovey's are staminates. McAroy's Superior appears to have lost ground, but it may be, because it has been extensively confounded with McAroy's Extra Red, a similar variety, but having an inferior, brisk acid flavor.

Peabody's Seedling has not been sufficiently tested at the North as yet to warrant a special notice.

Several English varieties are spoken of favorably, such as 'Trollope's Victoria, Sir Harry, Sir Charles Napier, \&c.; but we apprehend they will mostly remain as pets in the amateur's gardens like the imported varieties heretofore introduced.

Crimson Cone is jet the principle market fruit around New York. It is handsome, fair size, brisk acid, bears carriage well, is easily cultivated, and moderately productive.

Among the Raspberries, Brinctele's Orange is gaining favor, and the same may be said of the Dorchester or Improved High Bush Blacketerry of Massachusetts.

The Cherry Currant is objected to, on account of its severe acidity.

The Delaware and Rebecca Grapes are creating no little furore in the Horticultural world. They are certainly of delicious flavor, and if very early, hardy and productive as represented, will prove to be decided acquisitions. Several other new varieties are spoken of, but their precise value is so uncertain, that we can afford to wait.

There is great encouragement at the present time to raise seedlings for the purpose of introducing new and improved varieties of all our smaller fruits, and not only cultivators generally, but amateurs, if they have but a small garden, will find much pleasure in these experiments.

New York, March, 1858.

The Author. 


\section{TIIE STRA IV BERRY.}

TH1s is the most beautiful and delicious of all our early fruits, and so easily cultivated and so uniformly productive, that every houselkeeper possessing a few rods of ground can have no excuse for not supplying his table with an abundance.

Mr. A. J. Downing said truly, "Ripe, blushing strawberries eaten from the plant, or served with sugar and cream, are certainly Arcadian dainties with a true paradisiacal flavor, and, fortunately, they are so easily grown that the poorest owner of a few feet of ground may have them in abundance."

In the language of Mr. P. Barry- "To grow large, handsome, fine-flavored fruit in abundance, it is not necessary to employ a chemist to furnish us with a long list of specifics, nor even to employ a gardener by profession who can boast of long years of experience. Any one who can manage a crop of corn or potatoes can, if he will, grow strawberries."

During many seasons we have had on trial in our 
garden from twenty to sixty varieties at a time, and although some were comparatively unproductive, yet the average cost of producing them for years has been less than fifty cents per bushel; beside the cost of gathering and value of plants, which were taken from our own garden. Others can, and have done, the same. We can refer to amateurs, market-men, farmers, and nurserymen in Western New York, who have raised them at even a smaller cost, both on a large and small scale. On a plot of ground fifty by sixty feet, we have repeatedly gathered over fifteen bushels in a season, under all the disadvantage of many varieties. With a good selection of kinds, and good attention, it is certain that one hundred and fifty bushels can easily be produced on an acre. We have on small beds grown at the rate of two hundred and fifty bushels to the acre, and we are assured that, on a larger plot, at the rate of two hundred bushels per acre has been gathered. It is almost as easy to raise extra-large, fine fruit, as it is small, indifferent berries; and it is a decided object. Fruit of high flavor, measuring from three to four inches in circumference, will command fifty cents per quart in New York or any other good market, as readily as small fruit will ten cents; while the labor of picking such large fruit is very small, and the pro duct much larger. The demand for extraordinary fruit is everywhere increasing. 
Of the many varieties on our own grounds one sea. son, more than twenty different kinds, without special effort, produced specimens four inches in circumference, while the largest were six. There is a positive pleasure in raising such fruit, and our aim in this work is to enable many persons to make that pleasure their own. The interest on this subject has so increased and become so well-nig. universal, that every village and neighborhood can call out a little company who will be glad to know how easily it can be done.

Mr. Downing says, "The strawberry is perhaps the most wholesome of all fruits, being very easy of digestion, and never growing acid by fermentation, as most other fruits do. The oft-quoted instance of the great Linnæus curing himself of the gout by partaking freely of strawberries-a proof of its great wholesomeness-is a letter of credit which this tempting fruit has long enjoyed, for the consolation of those who are looking for a bitter concealed under every sweet."

An unknown writer in the last Patent Office Report says, "The strawberry was described by Juan di Cuba in his 'Ortus Sanitatis,' in 1485, in which its medical and other properties are treated at length." He also eloquently says:- "When we contemplate the relations which the strawberry plant bears to other parts of nature-to the sun which expands its blossom-to the winds which sow its seeds-to the brooks whose banks 
it embellishes; when we contemplate how it is pre. served during a winter's cold, capable of cleaving stones-how it appears verdant in the spring, without any pains employed to preserve it from frost and snow -how, feeble and trailing along the ground, it should be able to migrate from the deepest valleys to Alpine heights-to traverse the globe from north to south, from mountain to mountain, forming, on its passage over prairie and plain, a thousand mingled patches of checker-work of its fair flowers and scarlet or rosecolored fruit, with the plants of every clime-how it has been able to scatter itself from the mountains of Cashmere to Archangel, from Kamschatka to Spainhow, in a word, we find it in equal abundance on the continent of America, from the bleak fields of Tierra del Fuego to Oregon and Hudson's Bay, though myriads of animals are making incessant and universal havoc upon it, yet nc gardener is necessary to sow it again-we are struc's with wonder and admiration at so precious a gift." 


\section{SITUA TION.}

A warm, exposed, and yet rather moist location is the best for a strawberry plantation.

If very early fruit be an object, select a side-hill gently sloping towards the south, with a liberal admixture of small stones or coarse gravel in the soil. This should then be protected on the north, west, and east by a high closed board fence, or a live hedge, in order to be very early; we have seen an artificial hedge of withered evergreen boughs that had answered an excellent purpose, and enabled the owner to realize fifty cents per quart for the crop, when otherwise he could not have so much anticipated the usual season, and would have been compelled to take twelve and $a$ half cents for the same fruit.

If late fruit be desired, then select a piece of land facing the north, and exposed. Low land is usually preferable to high, hilly land for the strawberry, yet it can eastly be raised on both; a little knowledge of its character will enable us to remedy the defects of the high ground. If the situation is near a spring of . water, where it can be irrigated, and is also susceptible of drainage, it is very desirable.

Though they will sometimes succeed when partially shaded with trees or shrubbery, yet they are best 
flavored in an open garden, with no shade but their leaves. Alpines, and some other kinds, planted in the northern shade of a fence or dwelling, will commence Later and continue longer in their bearing season.

\section{SELECTION OF SOIL.}

New land, recently disrobed of its forest, if of a deep gravelly loam, we think is the best adapted to the strawberry, and next, a sandy loam; but almost any soil, even the heaviest clay, can be prepared, by a liberal admixture of sand or gravel, so as to produce the finest quality and a large crop of fruit.

As has been intimated, as low, soft, moist, cool soil as can be procured, consistently with depth and thorough drainage, is best adapted to the strawberry; and yet elevated knolls, and even sand-hills, with the precautions above-named, have often succeeded well.

Wet, spongy lands, except with a porous subsoil susceptible of drainage; and high, barren hills, with a thin, flinty soil, are alike to be avoided.

The strawberry, however, is so retentive of life, that it will live in almost any soil; but it will not produce much fruit, unless the remedies are in some vay ap. plied to the ungenial soils. 


\section{PREPARATION OF THE SOIL.}

Clear the ground of weeds, roots, and seeds of all kinds, as far as possible, in preparation for thorough drainage, which in most soils should be attended to the first thing. The best drains are the earthen tile drains, from two to four rods apart, which should be so constructed as to be left open at both ends for the circular tion of the air, as well as the release of stagnant water. A brush or coarse stone drain is beneficial as a temporary expedient.

The strawberry is so sensitive to both drought and stagnant water that most of the best land in our country should be well drained and trenched, if we would receive in return uniformly large crops of fruit in all seasons. After draining, break up the soil as deep and thoroughly as possible with a subsoil plough, or trench it with a spade to the depth of full twenty inches. By this process the strawberry roots can penetrate far below the effects of our severest droughts, which never extend, in good soil, it is said, more than from five to seven inches below the surface. Where the ground is properly prepared, the roots penetrate to a much greater depth than is generally supposed.

The late Mr. A. J. Downing assured us that he had traced the roots of a strawberry plant in one instance 
through a shelving of rock and earth a distance of between four and five feet in length, in its search for watcr.

Inasmuch as the fruit is composed of so large a proportion of potash, soda, and lime-sixty-two parts in every hundred, as will be seen by the tables in this work giving the analysis of the strawberry and plant -we recommend next, that an application to the acre be made of twenty to thirty bushels of unleached or leached ashes, ten to twelve bushels of lime-either stone or oystershell-with two or three bushels of salt, which should be thoroughly mixed with the soil, if possible some weeks before the plants are set out. It should never be forgotten that a frequent breaking up of the soil with the spade or fork before planting and stirring it up with a long tooth rake afterwards as long as it can be done without disturbing the roots; laying every part of it open to the action of frost, air, and light, so that a portion of the soil, at least eight to twelve per cent. is reduced to the finest powder, is indispensable to the healthy action of the many thousands, yea, millions of visible and invisible fibrous roots of the strawberry; neither can we too strongly insist upon the fact that while the strawberry fruit loves a pure finely pulverized virgin soil, it loathes the whole class of rich stimulating manures. 


\section{MANURES.}

Leaf-mo'uld, decomposed turf or peat, bog earth, new surface soil or muck, wood ashes and lime with a little salt well composted are, we think, the best manures for the strawberry.

On old or exhausted lands deficient in life as well as nutriment, barn-yard and other animal manures are often used, we know with comparative success, but we much prefer the above manures where they can be obtained. In our garden soils or good conditioned fields we would simply apply ashes, lime, and salt. Plaster is injurious to the strawberry, but ashes leached or unleached are generally beneficial.

We have not used any barn-yard animal manure during the last six or eight years in the cultivation of the strawberry in our own garden, and it was simply a a matter of careful experiment which induced us in our favored garden spot to adopt vegetable manures, in preference. The animal manures were found to be too heating and stimulating in their character, forcing out a rank, strong growth of vines and runners, quite unfavorable to fruitfulness. It should always be borne in mind that the strawberry plant does not produce runners, leaves, and fruit, as a general thing, at the same time. When the runners start, it will be noticed 
that the fruit-bearing propensity of the plant soon ceases. On the contrary, we have had strawberry plants in the oper. garden, north, in a soil two-thirds river sand with one-third finely pulverized garden soil, that continued in flower and fruit from June until September without showing any disposition to start a runner, until, by the addition of a little guano-water in September, the runners started, and the blossoms and fruit, as usual, then ceased to appear.

The usual application of barn-yard, especially horse manures, without compost on strawberry plantations, besides producing an over-growth of runners and leaves, even before the earliest fruit is perfected, heats the earth where a cool moist soil is required; and also fills the ground with seeds producing troublesome weeds, and mingles the soil with undecomposed portions of the straw, which, coming into injurious contact with the fibrous roots of the plants produces disas. trous results.

Our first successful experiment with the strawberry was on new land, which gave us an enormous crop of fruit. In order to increase the crop still more, the next year, we forked in rich manure between the rows and gave them the best of care, and obtained monstrous vines and blossoms but not even a pint of fruit in the place of bushels-a perfect failure. We then trenched a soil three feet deep, made it rich and set 
Jut some splendid plants from a bearing bed of Hovey's Seedlings, with an abundance of staminates within four feet. The vines were very large and fine, but, alas! did not produce one quart of fruit when fourteen months old. We then removed most of the rich soil and replaced it with sand, and the same bed bore us three bushels of overgrown Hovey's the next season. With the soil thus reduced, the plants very slowly and reluctantly threw out any runners, but continued bear. ing largely without change for four successive seasons.

On or about the first of May, and again ten days or two weeks later, three times each spring, it has been our custom liberally to sprinkle our choicest beds with a solution in six gallons of water, of one quarter of a pound each of sulphate of potash, sulphate of soda (glauber salts) and nitrate of soda, with one and a half ounce of sulphate of ammonia.

We would not represent this application to be essential to the production of good fruit, but a continued series of experiments has proved to our satisfaction that it is valuable for amateurs, especially in increasing the size, quantity and superiority of the fruit.

The apparent effect seemed to be to arouse the plants from the torpor of winter and give them in the early spring a strong, vigorous impetus, and aiding in the development of healthy plants for the production of large fruit. 
We have often seen Hovey's Seedlings nearly twice the size of adjoining beds that were neglected in the application. The most favorable time for the sprinkling seems to be at the close of a warm fine day wher the crown of the plants are fully exposed.

Where the above solution cannot be conveniently obtained, one-quarter of a pound of sulphate potash, sal soda, glauber salts, and one and a half ounce of sulphate or muriate of ammonia in six gallons of water, or either of them applied alone, we have found useful as a substitute.

Liquid manures composed of cow or hen droppings, or even soap-suds, we have not found good fertilizers for the fruitfulness of the strawberry, but they will increase the runners and promote the growth of the plants.

It is expected that these liquid applications will be mainly confined to garden or amateur culture whero there is an especial ambition to raise superior fruit.

It will be seen from the interesting articles in ou appendix A, from C. F. Peabody, Esq., near Columbus Georgia, that his own observations and extended ex perience have led him to similar conclusions in regard to manures that are here presented.

Various other intelligent observers and successfuI cultivators, might be named in different parts of our country, who have been led to adopt the same conclu. 
sions. The strawberry wants good wholesome soil, in good condition; suitable for the production of good large crops of corn and potatoes, only let all the soil be pure and free of undecomposed manures.

It cannot be too often repeated, that if you give them the best, pure soil; very finely, deeply pulverize it, and place it in the lightest, cleanest condition, and keep it so; get good plants of good varieties, and never let any single plants be nearer than ten inches to any other, the results will surpass your largest expectations.

\section{TRANSPLANTING.}

This is a process to which the strawberry is most sensitive. The plant will live under almost any treatment, or any manner or time of transplanting, but will not always yield a full supply of good fruit unless this process is appropriately performed. First we speak as to TIME.

For large plantations, or for ordinary cultivators, the early spring is perhaps the best season; certainly it is the time when it can be the easiest and most successfully accomplished. The ground is soft and moist at that time, and the weather is usually favorable.

The next season generally recommended is the month of September. Plants can then be easily ob 
tained, and after the cool, moist fall weather has con. menced, the ground works easily, and there is not much difficulty in making them live. There is one danger, however, to be especially guarded against in fall transplanting; that is, the plants may not get so firmly rooted as to be enabled to withstand successfully the severe frosts of winter. A liberal covering of straw will assist in remedying this matter. The advantages gained over spring transplanting will be, the sarth will not pack so very hard around the plants in the fall, as under the hot summer's sun and rains, and the plants will not be so likely to be checked in their growth as in the droughts which often occur in Juno and July or August; weeds will not so multiplyonly a partial crop however can be gathered the next reason.

We have transplanted strawberry plants successfully for years, every month, from March until the 20th of October, without difficulty. With mulching, shade, and water, judiciously applied, it can be well done at any time. For our own planting, we prefer the 1st of July for several reasons. The ground, if thoroughly prepared then, will not be subject to become so hard packed. The weeds will not be so troullesome. If the plants get well started, and are not checked in their growth, they will produce very nearly a ful crop of fruit the following spring. We have found that these 
advantages will amply repay the little extra care in mulching, shading and watering. Ten or fifteen àzys' later planting will, seriously lessen the first crop, accord. ing to our observation. In spring planting, March will answer south of Philadelphia, and last of April and first of May for the north. None but careful, skilful cultivators however should transplant in midsummer.

\section{MANNER OF TRANSPLANTING.}

The best way undoubtedly is, to take the first runners as soon as fairly set, and remove them with a transplanting trowel, with the roots and earth undisturbed. This however cannot be conveniently done, except the plants are in the same garden with the new bed. Neither have we ever found the first runners more produrtive than the subsequent ones, unless they are stronger.

In most cases, plants come from a distance, and great care should be taken to get as large a proportion of the numerous fibrous roots as possible; and in order to do this, the ground should always be well saturated with water, either artificially or otherwise, hefore the plants are taken up, and then the first thing to be done, is to mud the roots, by dipping tnem in a little mud-hole made in the garden soil, where the water has been poured and stirred, until it. has become safficiently thickened with the soil to leave a good coating of mud on the roots of the plants 
as they are withdrawn. This greatly protects the plants on a short or a longer transportation.

For transplanting, the earth should be levelled and made as flat as possible. If raised into beds or hills, it will invite the drought, to which the strawberry plant has a decided aversion. The plants should then be set out, leaving the roots in as nearly their natural spreading condition as possible; with the fingers press the pure earth compactly around the body of the plant, being careful not to set the plant too deep. If there is any old bark or decayed portion of the leaves on the plant, remove it before setting out: an old plant will usually renew itself by sending out a new set of roots on being transplanted, and it should be remembered that the strawberry plant, while it places its roots, mainly, near the surface of the ground, yet a portion of its larger roots penetrate favorable soils to the depth of from two to four feet, and even a greater depth in some cases, as has been stated.

\section{DISTANCE IN TRANSPLANTING.}

The Alpines and smaller varieties should always be eight to ten inches apart, while the larger varieties should be allowed ten or twelve to eighteen inches. I'ut one plant in a place, and let no other remain nearer than the above distances, and it is not material to sucsess in cultivation whether you plant in rows, beds, or 
bills, if you do not hill them up. We often set out in rows, two feet apart, and leave the plants one foot from each other in the rows; or a method by which we have enjoyed great success in producing the finest fruit, has been to prepare a plot of ground, and cover it with strong plants one yard apart, and stimulate these temporarily, by a liberal application of liquid manures or soap-suds from the wash, to send out runners, which will soon supply the intermediate ground with plants of nature's own planting, which is a little better done than any one else can do it; care should, however, be taken to spread the runners so that the abeve distance of from eight to twelve inches can be preserved. Allowing plants to fill the ground too closely with runners, and permitting those runners to remain, defeats more good crops of fruit than almost any other error.

For field culture, set one plant in a place, eight inches to one foot from the next, in rows three feet apart, so as to leave room for a horse-cultivator to pass between the rows, care being requisite not to approach nearer than eight inches to full grown plants, particularly when approaching the fruiting season. This whole process of field culture is the same in its general principles with that in the garden; except, for the convenience of a horse-cultivator to pass between them, the rows should one way be planted the same distance apart as corn; then she same treatment as to clean 
cultivaticn, and even water and mulching, as far as con nient, is desirable. (See our article on that subject.)

\section{MULCHING.}

This consists in covering the surface of the ground with something that is not injurious to the plant, to protect it from the intense heat of the sun or extreme cold. From one to four inches in depth is the usual custom; the latter depth for pear, peach, and other fruit trees.

For the strawberry, we prefer, as soon as the plants are set, at whatever season of the year, to cover the entire surface of the ground, including the walks, with tanbark, new or old, to the depth of half an inch or one inch, care being taken that it is left very thinonly a slight coating-immediately around the crown of the plant. We have pursued this plan, and have never known a single plant injured by it: on the contrary, all the plants have been decidedly benefited. When using sawdust, we have sometimes been a little troubled with mildew, but never with tanbark. Some of our most intelligent horticulturists say it is a specific manure for the strawberry, which others deny; we find it, at least, the best thing brought to our notice as a mulch. It is excellent to retain moisture and keep the earth in finc cundition under it; very few weeds will 
WATER.

ordinarily trouble us, where the tan is one inch in thickness, and altogether it is excellent. Where tan cannot be obtained, sawdust will do, if not applied too thick. Leaf-mould is very good, if the soil is not already too rich. Straw is good, but green rowen or fresh-cut grass, if the seeds are not ripe, is better still; any thing, in fact, not injurious, that is convenient and adapted, can be used.

\section{W A T E R.}

The strawberry has a great relish for good, clear, cold water. We have often seen them take a strong shower-bath at midday, in the face of the hottest sun in July, without skrinking. A slight sprinkle, just to lay the dust, does not satisfy them, but a thorough soaking is what they delight in-say a pailful of water to every six or eight plants, or every four feet square of earth. If you say "this calls for a great deal of hard work," we answer then, do not repeat it so often, but do it thoroughly whenever attempted. A few weeks since, we sent a friend some plants of new and rare kinds. A drought prevailed, and we feared he would neglect them, so we called to see them, and found he had set out and sprinkled them in the lightest, most delicate manner possikle, and lost the most of them. Another friend to whom we gave a few 
plants at the same dry time, gave them a thorough and repeated drenching, and saved all his plants.

A garden engine is very convenient in a strawberry plot, for watering purposes, or a stream of water so situated as to irrigate, is better still. A water-ram, and water brought up in pipes, will accomplish the same thing. Ordinarily, during the bearing season, sufficient rain falls, so that very little watering is needed: some seasons are so wet that no water is needed until the bearing season is over, and then the plants do not particularly require it; but a drought will soon compel the strawberry to cease bearing in ordinary soils. The remedy or preventive is deep soil and water, water, every day, and sometimes every night and morning. The evening, just at sundown, is the best time to water plants; and in some cases it is desirable that the water should have been exposed to the sun and air before being applied, but we do not think this is necessary for the strawberry.

\section{CUITIVATION.}

Most persons bestow, erroneously, most of their labor in raising strawberries on their cultivation. On the contrary, if our directions so far are strictly fol lowed, the work is mostly done, except gathering the fruit. We have very little work to do in the way of 
cultivation after planting, except watering and occasional pulling of weeds which appear through the tan, and neither of these ordinarily requires much time or labor. They must be kept clean and in good order, but we are very careful not to allow the hoe to be used nearer than eight inches to any full-grown plant, and, consequently, it is seldom or never used about the beds after the first month's planting. The reason is, the numerous fibrous roots so interlace and fill the ground for a space of six or eight inches around the plant, coming so completely to the surface, that the use of the hoe will cut off great numbers of those little roots, and we are unwilling to have our plants maimed in this way. It certainly greatly injures their bearing. The fork or spade should be kept at the same distance, for the same reason. The only time during the year we loosen the soil in our beds with the fork, is jiamediately at the close of the season of bearing, sel cting the time when the ground is moist. And yet, re repeat, the strawberries must be kept clean; a d the reader may here ses a reason for all the minute a id particular description we have given in the prepsration. It needs to be thoroughly done, because-it cannot well be remedied afterwards. The plants will not admit of freely working among them, except with the harıd, if not kept at an unusual distance from each other, witb 
out reducing the crop of fruit. If our object is large and abundant fruit, the roots must not be disturbed.

One qualification to the above: When new plants are set, unless prevented by mulching immediately, we, as often as every three days or week, for a month or so, hoe or rake the ground freely, and always stir the soil as close to the plants, as often, and as much as possible, only being cautious not to disturb the roots. On no account hill up the plants in the cultivation, or elevate the beds in good soil.

\section{FIELD CULTURE.}

Although most of the processes herein detailed for the garden are equally appropriate for those who are largely cultivating for market purposes, yet that class of persons are now becoming so numerous and important, particularly in the vicinity of our cities, that a general article, summing up the whole matter, may well be prepared for their especial convenience and benefit. Some points are so essential as to bear a distinct repetition.

Select from your farm as far as convenient a rather ow, cool, moist spot of ground, with an open, genial, pure soil; somewhat like that we often find on the margin 'f streams of water or muck swamps, or bog 
meadows, or get something as near to this as you can find. A fine gravelly loam is preferable, and it is better if the land has betn thoroughly cultivated with corn or potatoes for a year or two previous, so as to leave the land in a light good cundition, with the weeds, roots, and seeds mostiy decomposed. The land should be well drained at once, for it will pay to do so. In September, on the removal of the crop of corn or potatoes, plough the ground well and subsoil it deep. Early in December apply to each acre of land ten or twelve bushels of lime-old will do-and two or three bushels of common salt, and then with deep ploughing break up the soil again, throwing it up into ridges as far as the plough will do it, so that in the most exposed rondition it may be well prepared for the combined action of the snow, frost, air and light of the approaching winter.

In the spring, as soon as the ground is in order to work to advantage, apply thirty bushels leached or unleached ashes to the acre. If the soil is poor, or not in tolerably good condition, we would the fall previous take the lime, salt, and ashes with an equal quantity of good muck, or marl, or woods' mould, or good turf or surface soil and make a compost heap. Keep it moist and often stir it, and apply it all to the ground in the spring instead of putting on the lime and salt with the December ploughing. Perhaps it might be 
well, however, to divide the lime and salt and put haif of it on the land previous to the December plough. ing, and the remainder put into the compost heap.

If the land is too light and sandy it will be benefited by an additional moderate application of clay. If the soil is too heavy add sand or bog earth; if heavy and poor, put on a light coating of good loam or muck, and if you prefer animal manure, choose that of the cow or hog, instead of the horse which is too heating. If coarse gravel, add loam. It will be the best econo. my to attend thoroughly to all these things, for they will pay well. Nothing unnecessary is here specified. The products per acre from a field of market straw. berries vary from $\$ 100, \$ 200, \$ 100, \$ 1,000, \$ 1,300$ or more per acre, and the difference is so great as amply to remunerate for a most liberal application to the soil or of labor in the preparation.

As we have said, as early in the spring as the ground is in good working order, apply compost, \&c., as above directed, and then immediately plough deep and as well as possible. Then harrow and cross harrow until the soil is well pulverized, and level the ground and set out the strawberry plants, as has been stated, one in a place eight or ten inches apart, in rows three feet dis. tant, so that they can be cultivated with a horse cultivator between the rows; beside, while the plants are young all the weeds should be removed with a hee. 
care being taken, as often stated, not to disturb the small fibrous roots of the plant. We know some persons may think we insist too much on this point, and we also know there are those who have gathered fair but not large crops without much regard to the careless use of the hoe. The crop, however, will be so mucn increased that we shall be excused for so often repeating that it will well repay to weed by hand for the space of a few inches around each plant, instead of the more destructive and rapid process with the hoe. Let it never be forgotten, however, that a strawberry plantation must be kept clean throughout the entire season, As we have said, a slight covering of straw in winter, and a mulch of tanbark, straw, or grass, just previous to fruiting, will increase the crop.

Some persons, the first spring after the strawberry plants are set out, fill up the intervals of three feet between the rows with a row or two of beets. Inasmuch as the plants are not expected to produce much, if any, fruit the same season when set in the spring; therefore the occupation of the ground in this way is a very grod one.

When the plants get an early strong growth in the spring as we have recommended, care should be taken to remove the greater portion of the numerous runners which will strike previous to the coming winter. It is a very common and destructive error to allow too 
many plants to occupy the ground in the bearing sea. son. Often from five to fifty times as many plants can be seen on our strawberry plantations around the county as can bear fruit to advantage. It not unfrequently occurs that twenty plants on a foot square will scarcely ripen forty diminutive berries, whereas two well selected and cultivated plants on the same space will yield us one hundred noble berries of twice the average size; we repeat, the strawberry must have plenty of room, light, and air, to yield its full supply of fruit. The low, short, stout plants are the best to select and leave for fruiting. Prepare the ground by clearing it, and prepare the plants by thinning them out in the fall for the crop of fruit the next season, so that in the spring the latter will not be disturbed in the process of perfecting the fruit.

At the close of the fruit season stir up the ground with the cultivator, and prepare it for new plants whenever a renewal is necessary, and in such case, when the plants have become strong, run the cultiva. tor through the old rows, destroying them and leaving the plants on the intermediate spaces for bearing fruit the next season. Each year the plant should be as thoroughly prepared for fruiting as in the new bed. The popular varieties for market cultivation are Hovey's Seedling and Crimson Cone among the pistillate, and Large Early Scarlet and Iowa among tho 
stamnates. We recommend a trial for market purposes, and at first of course in a small way, of M[onro : Scarlet, McAroy's Extra Red, Moyamensing Pine, and Jenny's Seedling.

\section{PRODUCTION.}

The past year, 1855, was, on account of the frequent early rains, an unusually favorable one for the strawberry.

The crops were larger than usual, and the markets generally were well supplied.

An extended correspondence, personal examination and inquiry has been undertaken to ascertain, or at least approximate to, the consumption during the last season in some of our principal cities. From all that has been accumulated on the subject our estimates are as follows:

New York City 47 to 54,000 bushels.

Philadelphia 10 to 14,000 "

Boston 9 to 11,000 "

Cincinnati 11 to 14,000 "

We are assured that New York City received many days more than 500,000 baskets, or over 3,000 bushels for its own consumption, and for the supply of its sub. urbs. A single county in New Jersey from a single port, over twenty-five milcs distant, sent us by steam. 
boats during one day last season 200,000 baskets; and several years ago the superintendent of the Erie R. R. certified to the secretary, Mr. Marsh, that the evening train of that day brought in 893 bushels strawberries.

From all sources during the season we could have received scarcely less than $8,000,000$ baskets, which at an average wholesale price of $2 \frac{1}{2}$ cents per basket, (five baskets to the quart) would make an aggregate of $\$ 200,000$. It should be remembered that much of the supply of Brooklyn comes through the New York market.

Some single farmers around New York are cultivating thirty or more acres. Cincinnati reported 9,000 bushels strawberries in their market in 1851 or ' 52 .

We cannot learn that the common crop of the strawberry either around New York, Philadelphia, Boston or Cincinnati actually exceeds twenty-five to fifty bushels per acre, although we have instances reported around all the cities of 100 bushels, and even 130 to 140 bushels having been produced on an acre, or in that proportion; so that the returns given in to us of the avails varies from $\$ 100$ to $\$ 800$ per acre, and the prices obtained ranges from $12 \frac{1}{2}$ cents up to $\$ 150$ per quart. The latter price for the very earliest taken into Washington City from the vicinity. The ordinary return for an acre, in order to be satisfactory to the growers, we are told is $\$ 200$; and the expense of cul. 
tivating $\$ 15$ to $\$ 25$ per acre, with an additional expense of one cent per basket, or $\$ 150$ per bushel for picking.

It will thus be seen that in order to supply New York and vicinity with stramberries, about 1,500 acres of the choicest land in the vicinity is at present required, and the other cities named about 500 acres each in proportion; which is at least four times as much land as is either appropriate or necessary for the object, if the nature and cultivation of the strawberry was oniy as well understood as the raising of corn. A crop of 30 bushels of strawberries to the acre, is only about equal in proportion to a corn crop of 10 bushels on the same ground. We seldom see a large strawberry piantation which after the first year has not many more plants on the ground than can get light and air sufficient to fruit well. The consequence is, that our city markets are mainly supplied with inferior fruit, simply because some of the commonest kinds will produce a little, dwarfed, sour fruit, even under the worst treatment. Superior well-grown fruit will easily produce twice and four times as much to the acre, and command from twice to four times larger prices in our city markets. Making the avails and the dif ference from the same land, to be 25 bushels at $12 \frac{1}{2}$ cents per quart, or at least 125 bushels at $2 \check{5}$ cents per quart, or $\$ 1,000$ or $\$ 100$ per acre. In one instance the net profits exceed $\$ 800$, and in the others very little, if 
any. One hundred and twenty-five bushels ought to be only an ordinary crop, and $\$ 1,000$ the product of any fair acre of land.

We have often had small plots of ground produce in the ratio of twice that amount.

A writer in 1854 in the May number of the Albany Cultivator, from the old soil of West Haven, Connecticut, certifies to having realized $\$ 215$ from the sales of strawberries from 25 rods of ground, or at the rate of $\$ 1,300$ per acre!

In Hovey's Magazine, 1852, it is stated that Mr. Gore, of Maine, raised on a bed 11 by 43 feet at the rate of full 300 bushels per acre. How long in common fairness ought men to enjoy the stewardship of our choice land that is capable of producing such results, when they only equal one-thirteenth part of that amount! We would not dispossess them of their rights, but we beg of them to place the occupation of the land by sale or otherwise in more capable and effi. cient hands.

\section{RENEWAL OF BEDS.}

This should be done once in three or four years, and the same ground should be planted with corn or potatoes for one season, and receive an application of lime, ashes, and salt, as advised in the article on the 
preparation of the ground, before it is again used for strawberries. The bed might be made to bear well, by a careful renewal of the old plants by their run. ners, for ten or a dozen years, but this would require rather more skill in cultivation than most persons possess.

Every year or two, if a strong runner has struck itself beside an old plant, we pull up the old plant instead of the runner, and are constantly thus renewing them. We always leave the best plants. The field cultivator has only to clean off the weeds, and prepare the soil in the spaces of three feet between the rows; allow the runners to cover that ground; then drive the cultivator or plough through, turning under the old row of plants; thin out the new ones to proper distances, and his system of renewal is complete.

\section{WINTER PROTECTION.}

Our experience is in favor of a slight winter protection. It costs comparatively but little time or expense, on the approach of severe winter weather, to hastily scatter a thin coat of straw or old leaves over the plants; and they come out in so much better condition in the spring. and even the hardiest kinds bear so much better crops for it, that we never neglect it. Like mulching, almost any thing free from weeds, that 
will not smother them or mildew, will answer the purpose, but clean straw is preferable, except they need the decaying leaves.

Some years ago, we had an aged neighbor, who stood almost unrivalled in the cultivation of the strawberry. One season he set out, on the first of July, about one-fourth of an acre of fine Hovey's Seedlings. He almost constantly and carefully worked among them with the hoe, the rake, and water-pot, and I never saw a plot of so fine strawberry-plants as these had become on the approach of winter.

The old man was "very much set in his way," and among the things his creed discarded, was mulching strawberries; so, against my repeated remonstrances, he left them for the winter without mulching; with his usual preparation, which consisted in placing a halfinch deep of good earth around each plant, in a circuit, to the width of six or eight inches, leaving the surface, scolloped inwards towards the centre of the plant. The winter proved a severe one, and the old man was saddened in the spring, to find his fine plants drawn out of the ground to the length of three and four inches, and laid flat on the earth. One-tenth part of the labor he bestowed in hilling his plants for winter, appropriated to covering them with a little loose straw, would have saved them all. 


\section{EVER-BEARING STRAWBERRIES.}

The Bush Alpines have always borne a succession of crops during the season, when planted in the north. ern shade of a fence, and well taken care of, watered, mulcher, \&c.

Some three or four years ago, the New Orleans Picaywine announced that Mr. Henry Lawrence, a gentleman of that city, had succeeded in obtaining a seedling, called the "Crescent Seedling," which bore an abundance of large fruit for a continuous period of six or eight months or more, from Narch to December. We wrote to Mr. Lawrence, and his answer confirmed all the paper had stated; and he sent us in succession four or five different importations of plants of the Crescent Seedling, by the steamer and otherwise, until at last we succeeded in causing them to grow, ana. awaited their bearing season, when, alas! they only bore a moderate crop, and caased bearing as early as any other variety in our ground; thus proving a failure, as far as perpetual bearing was concerned, under our ordinary mode of cultivation. 'The plant has extraordinary vigor, a rampant staminate, exceeding all varieties we hrve ever seen in multiplying its runners. The experiment convinced us that it was 
not the variety, so much as the cultivation, and soil and climate, which gave it its continual bearing pro. perties. Some experiments since made with this varicty, in soils so reduced as to be little else than coarse sand, favor this idea. Mr. Lawrence wrote me at the first, that he reduced his soil by three-fourths of pure river-sand; and, although I reduced my garden-soil considerably, yet it remained still very much too rich for the Crescent Seedling to develop its perpetual pro perties. The various experiments, however, were by no means lost.

About this time, it was announced by the press that Charles A. Peabody, Esq., the horticultural editor of the Soil of the South, near Columbus, Georgia, had succeeded, by reducing the soil, and with plenty of water, in making two well-known northern varieties-the Large Early Scarlet, and Hovey's Seedling-develop perpetual bearing qualities under the hot summer's sun in Georgia, furnishing fruit in quantities, from March till January. If this was the case in Georgia and New Orleans, could we not hope, by similar means, to extend our strawberry season north, during the months of July, August, into September? In. October last, in an interview with Mr. Peabody, he gave it as his deliberate opinion that, by the process he detailed and pursucd, we could easily have an abundance of fruit from our strawberry vines until frust came. We take 
pleasure in inserting Mr. Peabody's plan and directions in full, in his interesting articles, in the Appendix, A.

On the 20th December last, Mr. Peabody took up a few plants in fruit from his garden, and placed them, with the soil attached, in a basket, and sent them by express to Messrs. J. M. Thorburn \& Co., 13 John street, New York. On their arrival, on Christmas Day, they were well loaded with large, ripe Hovey's and Early Scarlets, together with a large variety of green fruit, of all sizes, from that of a pea upwards to full-grown berries. They remained on exhibition in their windows some two weeks, when they were politely handed to us, and we had them potted in a greenhouse, with soil composed mostly of sand. The plants all grew finely; in March they came into blossom, and in May into ripe fruit. The foliage was very small, but healthy. They continued in blossom and bearing during the months of May, June, and July, without sending out a single runner, and some of the plants at the present time (the 14th of August) are in blossom, and have not started a runner. On one of the pots which had no runners started, we placed a very little rich soil, and in a week the plant threw up vigorous runners, caused by the slight addition to the richness of the soil.

The inference we draw from all this is, that no variety is ever-bearing under our usual manner of 
treatment, but that most kinds can be so trained, that, with a soil reduced largely enough with sand, and only vegetable manures applied, and plenty of water, and mulching when needed, they will continue to pro. duce fruit until the approach of frost. The whole tendency of our experiments in strawberries is in this direction. Professor Page has, in Washington City, it is stated, induced the Alice Maude to adopt the everbearing habit. E. P. Brooks, Esq., of Elmira, N. Y., had the Hautboys in bearing in the open garden in September and even in December, 1855.

Amateurs and others will do well to try the experiment on a small scale, until they perfectly succeed; and then the large price of a dollar or more per quart, which the markets of New York, Boston, and Philadelphia will pay for such fruits in August, will amply repay for the production on a large scale. Learn well, by observation; all the habits and tendencies of the strawberry in this regard. and we think the thing can be easily accomplished.

\section{SEXUAL CHARACTER.}

We now come to the great battle-ground of the giants, but will not enter the lists, if we may be per. mitted to quietly state a few things as our opinion, without intending to reflect upon, or having even re. 
mote reference to, any persons. It is very easy to see the manner in which some have been led into error, viz.: the mixture, well-nigh universal, of different kinds of strawberries-an error productive of untold injury to successful cultivation. We have never seen two kinds of strawberry that might safely run in the same bed. On no account suffer it. The poorest kind will multiply its runners the most rapidly, and drive the well-bearing plants from the bed; particularly is this the case, where that poor kind is a staminate. We think the direction given by the late Mr. Downing and others, to place the staminates on each end of the same bed, with the pistillates in the centre, an unfortunate one, for the beds and the plants are usually very soon destroyed in that way. We are very particular to place our staminates a greater distance from the pistillates: if 30 feet to 60 feet off, it is better. The bees and wind carry the pollen, and opposite sides of the garden, if the distance is 100 feet, will, we think, be found near enough to answer the same purpose. Neither would we.allow pistillates, such as Hovey's Seedling and Burr's New Pine, to run together, but be very particular to keep each kind distinct and apart. We think it is Mr. Longworth who has stated, that if we place a single staminate plant, like the Large Early Scarlet, in the centre of a productive bed of a pure pistillate variety, in less than two or three years. 
that one plant will drive every good fruit-bearing plant out of the bed.

This is one reason why so many strawberry beds fail after the first bearing season; so we repeat in the strongest manner, get pure plants-diffcult, we know -and on no account permit any two linids to run together; place boards on edge between them, or ir some way protect them from each other.

After this episode on a very practical point, we may be permitted to say, there are strawberry plants we call staminate, because they exhibit to the eye very distinct stamens. Our plate will illustrate this. Another kind we call pistillate, because the naked eye can discover developed in the blossom only the pistils. Most of our intelligent horticulturists assure us, that the best staminates will only produce a part of a fair crop of fruit, while the pistillate varieties will produce no perfect fruit at all, without being impregnated by some staminates in the vicinity; but when thus impregnated, the pistillates produce an abundance of the finest fruit.

The interesting and accurate experiment of $\mathrm{Mr}$. Huntsman, in the Appendix, C, sets this matter in a very clear light.

Some of the staminates of recent introduction, like Walker's Seedling and Longworth's Prolific, are so very desirable, that every cultivator should have one 
or both: it is, therefore, only important to notice the presence of the staminates in every collection of varieties, keep them distinct, and no sacrifice is required to conform to this theory, which seems to be pretty universally established. Mr. Longworth's article in the Appendix, D, gives an interesting account of its discovery.

Another series of plants are called Hermaphroditclike Long'worth's Prolific-because both stamens and pistils are in a greater or less extent developed, and they are represented to bear well, being alone.

The great war that has raged so fiercely on the bor. ders of the strawberry kingdom during the past year or two, has been on the point, whether staminates ever cnange to pistillates, or vice versâ. For many years we have noticed, with scrupulous care, these distinct characteristics of the various strawberries when in blossom, and we have never seen the first symptoms

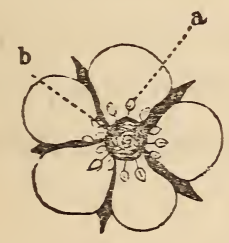

FIG. 1.

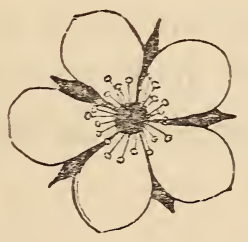

Fig. 2.

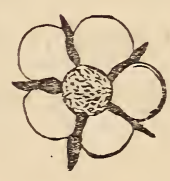

Fra 8.

Fig. 1. A perfect flower furnished with stamens and pistils. $a$. the stancus. b. the pistils hermaphrodite.

Fig. 2. A staminate or male flower.

Fig. 3. A pistillate or female flower. 


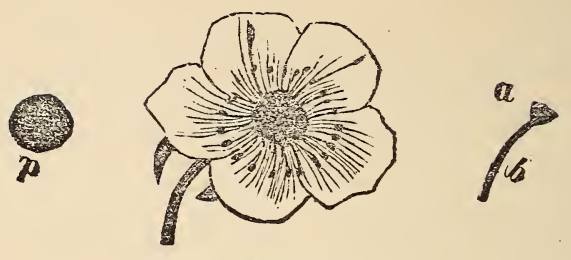

Fig. 4.

Fig 4 A perfect flower, with a stamen and pistil detached. $a$, the snther. $b$, the filament. $p$, the pistil.

of change in any variety. We do not know that a change in open-air cultivation is now much contended for from any quarter. We think the mixing of plants causes staminate and pistillate blossoms to be seen together. In forcing, we are told, by high authority, that some plants, like the melon, \&c., change their sexual character, and why not the strawberry? We do not know that this point, that the strawberry does so, has yet been fully established.

The English varieties are mostly staminates, and bear fruit of extraordinary size and flavor; but we think not in so large quantities as some of our pistillates. Certainly all the English staminates prove com. paratively only second-rate in our soil and climate. 
FORCING.

\section{FORCING.}

On this point our experience is very limited, having been confined to small experiments during the past winter: we therefore give the best information we have been able to obtain, from the highest English authorities.

In the London Gardener's Chronicle, edited in the Horticultural Department by Professor Lindley, we find the following directions from that most eminent horticulturist, Mr. Paxton:

"Select for this purpose, in the middle of August, a sufficient number of the best runners from approved kinds to have choice from, and plant them six inches apart, in beds, upon a strong border in a dry and sheltered situation. As soon as the leaves have withered, mulch them lightly with well-rotted manure, and if very severe weather occur, protect them for the time with fern or litter. They must be kept the following spring free from weeds and runners, removing also any flowers as they appear. Towards the latter end of May or beginning of June, whenever dull or rainy weather may occur, remove them carefully into forty. eight-sized pots. It is optional with the grower, whether one, two, or three plants are put in one pot, 
according to his object being quality or quantity; but we, desiring fine fruit in preference to number, only place one of the strongest or two of the weaker in one pot, using enriched melon soil or turfy loam. Place them, when potted, in a situation where they can be readily shaded for a sbort time, and receive regular supplies of water if necessary. About the latter end of July, or early in August, these pots will be filled with roots, when the plants must be repotted into flat thirty-two-sized pots, usually termed strawberry pots, and at this time plunged in old tan or coal ashes. The best manner of plunging them we find to be, forming beds wide enough to contain five rows of pots, when plunged, upon a hard or gravelly surface, to prevent them rooting through, the sides supported by slabs of the same width as the depth of the pots, and filling them up with old tan or ashes; the plants remain here until wanted to take in, and are easily protected from severe frosts. It will be found an excellent plan to preserve the latest forced plants, which are not much exhausted, for forcing the first the next season; these, from their long period of rest, and well-ripened buds, are predisposed to break earlier and stronger than the others; some of them; if the autumn is moist, will be excited, and produce flowers, which must be immediately pinched out; they should have their balls earefully reduced, and be repotted in larger pots early 
in August, protecting them from the late autumnal rains, and from frost."

"For succession," Mr. Paxton says, "strong runners are taken up in September, and planted about six inches apart, in manured and well-prepared beds, four feet wide, in a somewhat sheltered situation; there they are allowed to remain until the following July, during which period they must be kept very clean from weeds, have the flowers and runners regularly pinched off, and be watered whenever likely to suffer from drought. About the middle of July they are potted in small thirty-two-sized pots, two plants in a pot, taking the greatest care that neither roots nor leaves are damaged in the operation, and an important part of it is to press the earth firmly about them; the soil used is two parts loam to one of well-rotted dung. Beds which will hold five or six rows of pots are then formed in the following manner: Level the surface of the ground, and spread upon it a layer of coal ashes; above which must be nailed firmly slabs, or any rough boards, as wide as the depth of the pots, which are then to be plunged to the rim in spent bark or ashes. All that they will here require is attention to watering when necessary, and a slight protection with fern, or other light covering, during severe frosty weather. I aiways preserved from 300 to 400 of the latest forced plants of the above description, and after having care- 
fully reduced their balls, repot them in large thirty. two-sized pots in July, treating them afterwards precisely as the others. I find these, by having their buds formed early, (through the slightest forcing they have received), and becoming very strong, are admirably adapted for the first crop, and always repay me for the extra trouble. Begin forcing with a temperature of $40^{\circ}$, increasing to $50^{\circ}$ when in bloom, and to $55^{\circ}$ when ripening."

"Mr. Brown, gardener to Lord Southampton, at Whittlebury Lodge, near Towcester, says, that Mr. Paxton's method of preparing strawberry plants for forcing is a good one where time and trouble are of no consequence: but for the last fifteen years he has adopted a plan which answers well, and by which good strong plants are procured in one month from the present year's runners.

"The compost used in good strong loam, well mixed with rotten dung from the hot-bed linings; twentyfour-sized pots are the best for Keene's Seedlings, and thirty-twos for Grove End Scarlets. The latter variety answers for early forcing better than any other sort, when strawberries are wanted by the end of March.

"Having filled the pots with the compost, they are removed at once to the strawberry quarters, and arranged on each side of the rows, among the runners. The middle of July, when the plants are emitting 
roots, is the proper time to begin the operation of layering: having previously prepared a quantity of pegs, the runners that are rooted into the ground are carefully removed, and their roots inserted in the pots and pegged down. Put three plants into the twenty-four pots, and one in the thirty-twos; they immediately begin growing, being supported by the mother plant, and will only require occasional watering in dry weather.

"When the plants are well rooted, which is in about one month, detach them from the old plants, and remove to their winter-quarters.

"Beds are prepared for them with a bottom of coul ashes, and they are plunged in old tan; each bed surrounded with a stratum of coal ashes six inches wide, and as high as the top of the pots, which prevents worms from working amongst them."

\section{SEEDIINGS.}

Since the introduction of Hovey's Seedling, this department of strawberry culture has had new life and vigor infused into it, and has resulted in affording high gratification to those engaged in it, and proved of decided benefit to our country.

This fruit is so soon and so easily raised from seed, that the process invites to a very attractive series of $3 *$ 
experiments. Almost any one can experiment in a small way; and the person who shall produce a strawberry of the size of Hovey's Seedling, or of the size and productiveness of McAvoy's Extra Red, oombined with the exquisite flavor of Burr's New Pine, will be a benefactor.

Perhaps the easiest way is to select the largest ripe berries of the best class of pistillates, raised in close proximity to one of the best staminates, and crush them in a bed of pure sand, mix them, and let the seeds dry and ripen for two weeks or a month; then sow them in light soil, in a partially shaded spot in the garden, carefully water, and in winter protect them with a covering of straw; in spring transplant them, one plant in a place two feet apart; carefully remove all runners until the plants have borne; seiect the best for further trial, and throw the rest away. A better way, if convenient, is to sow the seeds and sand in a cold frame, provided in a northern exposure, and transplant as above directed.

\section{CLASSIFICATION.}

Mr. Elliott says, "Authors have classed the strawberry as Scarlets, the original type being our wild strawberry; PINES originating from the Pine or Surinam strawberry; Woods and Alpines from the 
common wood strawberry of Europe; HAutBoIs, or High-wood from Bohemia; CHILI, from South America. "The SCARLETS are designated in their character by small flowers; long, thin, light-green, sharply serrate leaves; acid or sub-acid fruit, of bright scarlet color, with seeds deeply imbedded." The Large Early Scar. let, Methven, Duke of Kent, and others, are of this class, and yet the flowers of the first two are rather large. "The Pixes are designated by large flowers; broad, dark-green leaves; fruit of pineapple flavor, and generally soft in texture; seeds slightly imbedded." Hovey's, Black Prince, Burr's New Pine, British Queen, \&c., are of this class, and yet Horey's and New Pine have quite small flowers: the two others are large.

"The AlpiNes and Woods have small flowers, perfect in their organs; small, thin, light-green leaves; fruit small, sweet, and separating freely from the calyx.

"The HautBois have large, pale-green leaves, on tall foot-stalks, the fruit-stalk tall and erect, the fruit of a dull red or purplish color.

"The CHil, designated by hairy, thick, obtusely serrate leaves, fruit pale red and insipid.

"The Grees Strawberries have light-green foliage, plaited fruit, solid flesh, so unworthy cultivation as rarely t八 be found in this country. 
"We have dropped the arrangement into classes in order."

The above classification is a distinct one, but we do not think quite correct, neither can we find or make one that is both distinct and correct.

\section{SEIECTION OF VARIETIES.}

This is a point of no small difficulty. One person wishes only the finest flavored varieties for his own table, of which Burr's New Pine and Swainstone's Seedling are the head; another wishes all the showy and fancy varieties, such as the Bicton Pine, Black Prince, Alice Maude, \&c.; another, still, cultivates for market, and wants large, bright-colored, solid-fleshed: productive fruit, like McAvoy's Extra Red, Moya. mensing Pine, and Walker's Seedling. Again, the manner of the cultivation of some persons will conform to some varieties, and be opposed to others, perhaps superior; or some soils and climates are naturally adapted to some varieties, and unadapted to others, so that the custom we have adopted in years past, we would recommend to those going into the cultivation of the strawberry, viz.: Obtain a plant or two of several of the best varieties named, and cultivate them experirnentally for two or three years, and then select the most successful ones and discard the others 
Another difficulty arises from the new developments constantly making, which tends to evalt a neglected variety in some sections of our country, and depress a favorite one in other parts, so that we shall, it is pro. bable, in future editions take the liberty of amending or changing our opinions respecting some of the different varieties named, as time and enlarged experience shall demand.

Another point of delicacy still arises, from the fact that many of our friends have produced seedlings of which they think and speak in the highest terms; but from what little we have seen of them, and their trial being almost exclusively in the hands of the originators, we do not feel authorized to speak of them pro ur con; besides, many seedlings are constantly produced by our nurserymen, some good, and many not so good, who cultivate them frequently, as they do their plants for sale, in crowded beds or even in compact masses, or in the partial shade of trees or shrubbery, on old soil, so that their mode of trial is often of little value in developing or determining the real character of the plant.

Some varieties we do not name will doubtless prove superior, and we would not intimate that some of the varieties we are not acquainted with may not prove of the first class.

We shall speak mainly and freely our own experi- 
ence and observations of the peculiarities of the dilferent kinds as manifested to us during the last ten or twelve years or less, and in a plain, distinct manner. give our present views of them, not being confined to or having much reference to the usual condensed pomological descriptions or classifications, which we think are not so important to the popular mind, and we are not writing a work to instruct botanists or learned pomologists.

The first six varieties named and described would, all things considered, be our first choice in a selection confined to that number. The next twelve will follow very nearly, not entirely, in their regular order as our next choice, reference being had to the particular descriptions for the prominent characteristics of each, as fitted for the amateur, the family, or the market-man.

\section{MIOATOY'S SUPERIOR,}

The new $\$ 100$ prize seedling of the Cincinnati Horticultural Society in 1851 . It was originated in that city by Mr. D. McAvoy, in 1848, on loamy clay soil underlaid with limestone, and was called out by the offer of a premium of $\$ 100$ by that Society, at the instance of that energetic horticulturist, Nicholas Longworth, Esq., for a pistillate strawberry which should prove, on a four years' trial, to surpass all other known varieties in size, flavor, an 1 productiveness. 


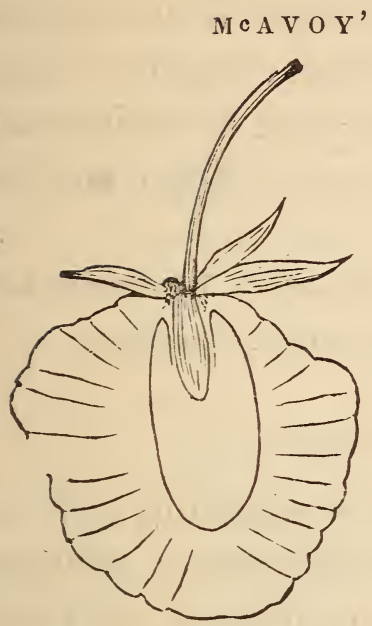

FIG. 1

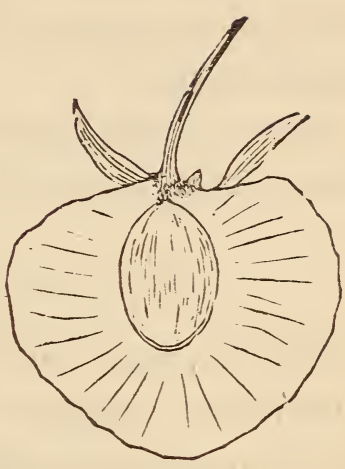

FIG. 2

The committee concluding that this fulfilled the conditions, reported in its favor, and the report was adopted by the Society. In September, 1851, we obtained two plants, and in so far as our observation of it las extended in our own and several other gardens, in different portions of our country it is superior, in average size and productiveness, to any other variety we have seen; and while it is good, and when properly ripened of high flavor and delicious, yet we do not think it equals, much less surpasses, Burr's New Pine in flavor. It is pistillate, hardy, vigorous, dark serrated leaf, long foot-stalks, trusses of fruit full and usually well formed, but occasionally a berry not entirely filled out; the runners are not so numerous as to be troublesome 
fruit very large, often over five inches in circumference, rich dark color until over-ripe; irregular, conical, roundish; large seeds, slightly sunk; flesh crimson and white, tender, juicy, with a core of rather open and coarse texture.

Ripens medium season, and rather too tender for a market fruit, except for short carriage distance.

\section{HOVEY'S SEEDLING。}

This has been truly called a noble fruit, and is an honor to the originator, Mr. C. M. Hovey, of Boston. It has undoubtedly taken more prizes in the various Horticultural Exhibitions of our country, from Maine to Louisiana, than any other variety, and it retains the same position at the present time, although it is not, equal in flavor to Burr's New Pine and others, or of the average size of McAvoy's Superior and some other varieties; and in almost every quarter, we hear more or less complaints of its fickleness in bearing, mingied with the strongest approvals of its productiveness.

Notwithstanding all murmurs, its flavor is good when well ripened; it is too often picked and tasted when first colored and unripe; and some of its berries so surpass all other varieties in size-often five and six and sometimes over eight inches in circumferenceas to carry along the judges at our exhibitions; and the size under good cultivation always proves satisfactory. 


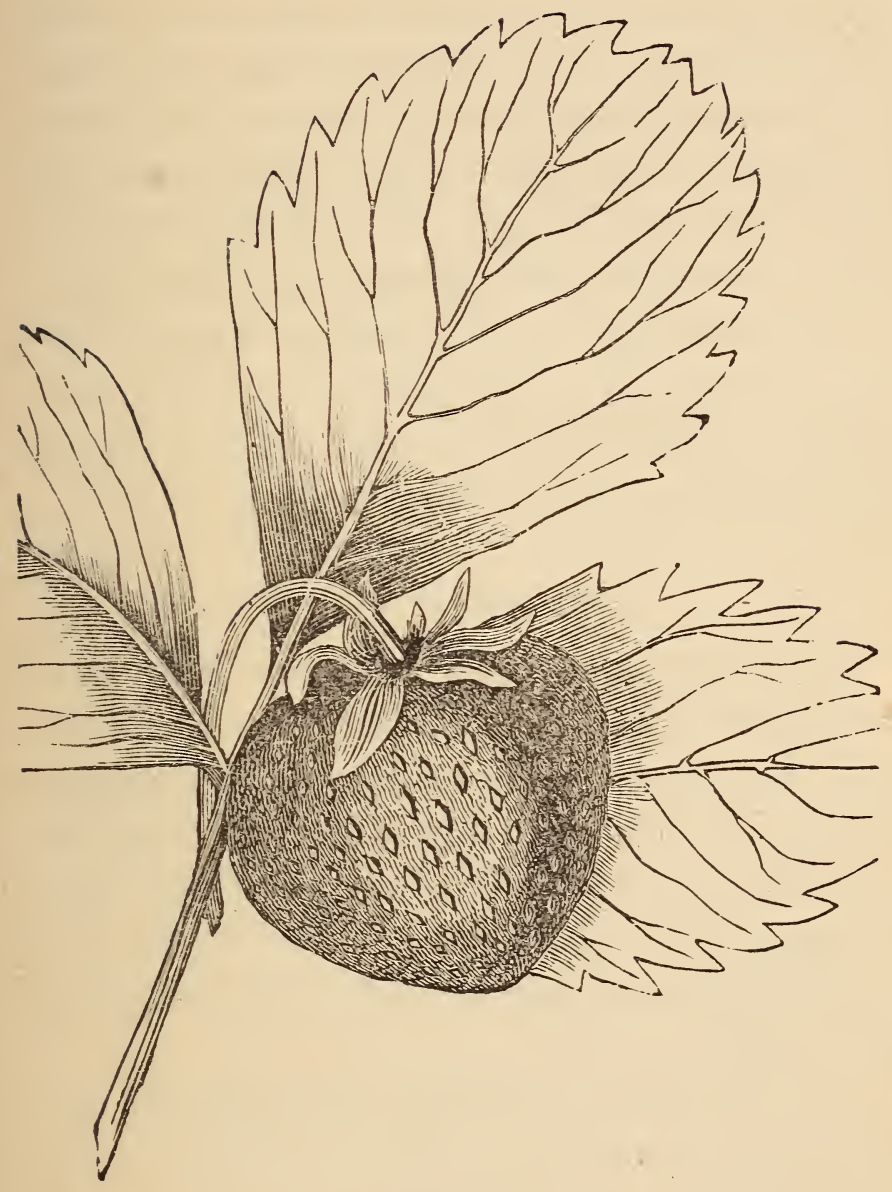

FIG. 3.

We have, in times past, been embarrassed by its failure in bearing, but we are inclined to think it was in a great measure owing to our want of knowledge of its habits, and consequently erroneous cultivation. It 
requires a great deal of water, or moist soil, and will not bear so rich soil as Boston Pine and many other kinds; and the simple reduction of the soil to the common grade has sometimes changed the barren into productive plants. It originated in 1834 . The vines are vigorous, leaves large in rich soil, rather light green, and fruit-stalks are of good length. Fruit is very large, roundish-oval, conical ; color, rich scarlet; seeds slightly imbedded; firm flesh; well adapted for market, and of medium seasnn; flowers pistillate.

\section{MONROE SCARLET.}

This variety has not been so extensively known or so largely tested as Hovey's Seedling and Burr's New Pine. It originated in Rochester by those enterprising nurserymen, Messrs. Elwanger \& Barry, and was first exhibited by them at the June meeting of the "Horticritural Society of the Valley of the Genesee," we think in 1850, where we first saw it, and took a plant home with us.

We introduce it in this connection, because we think it will prove remarkably productive. Such has been the case in our trials of it; it has uniformly surpassed all others in bearing. We have counted over seventy ripe berries of good size, the largest measuring four and three-fourths inches in circumference at one time, on a single plant less than one year old. A friend 
south of Washington City, to whom we sent a fer gen. uine plants a year or two ago, writes: "Monroe Scarlet proved with me last season exceedingly productive, and nearly covered the entire surface of the ground with trusses of fruit. It is a decided acquisition." We are aware that the Alpines, and some other kinds, will produce many berries in a single hill, but they are very small fruit, and will not produce near the quantity. It is a hybrid of Hovey's Seedling and the Duke of Kent. The plant is very vigorous : pistillate; fruit large, roundish, short neck, and beautiful, of good fair flavor, hard flesh, a long bearer, and good for market; does well partially shaded.

\section{BURR'S IEW PINE.}

This variety originated in Columbus, Ohio, in 1846, on a clay soil, and is remarkable for its agreeable, delicious, aromatic flavor, surpassing all other varieties; and also for its early bearing and uniform productiveness. It is usually of large medium size, although we have seen on exhibition large dishes of fruit

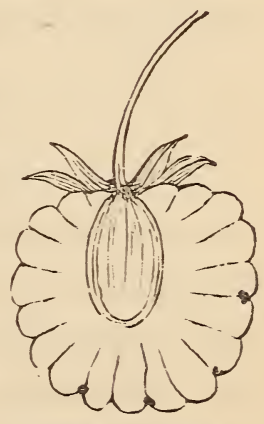

BURR'S NEW PINE. measuring nearly four inches in circumference, and have measured single specimens from our own garden full four and a quarter inches; and when thus well 
grown, and on exhibition, it will bear off the first prize from Hovey's Seedling, and all other varieties; yet it is, under ordinary cultivation, nearer the size of three inches in circumference. It is a great farorite with families of exquisite taste, either for the hand or for the table, and we have proved it to be the earliest of sixty varieties in the same garden to ripen its fruit, and one of the latest to cease bearing; and occasional plants have produced a small second crop in the autumn, while standing without watering in the open garden. The fruit is large, round, conical and even; color, pale red; seeds very slightly sunk; flesh, whitishpink, sweet, and too tender for a market fruit; quite productive, and berries perfect; the foliage is large, and the plant is vigorous and hardy. It is indispensable for private gardens. Pistillate.

\section{LONGWORTH'S PROLIFIC.}

The two remaining plants of the first six are stami. nate, or hermaphrodite. This variety originated in Cincinnati at the same time with McAvoy's Superior. Mr. Longworth furnished the seed for both plants to two cultivators, McAvoy and Schnecke, the former of whom produced the Superior, and the latter this variety, which at first was called "Schnecke's Herma. phrodite," but afterwards named by the Cincinnati Eorticultural Society, "Longworth's Prolific," in 
honor of Nicholas Longworth, Esq. It is a great favorite with the gentleman whose name it bears, who says "it will do what no other variety in this country or Europe has ever done-bear a full crop of good fruit standing alone." In a note to Mr. Barry in the fall of

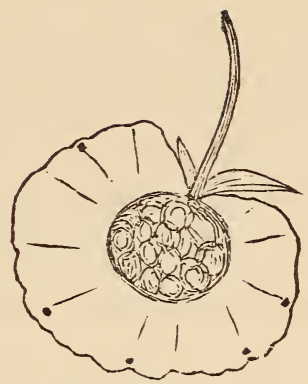

LONGWORTH'S PROLIFIC. 18503, he says, "You will find the Prolific of more value than all the seedlings ever raised." Mr. Elliott, in his Guide, says, "For market culture we regard it of more value than McAvoy's Superior;" and we have heard Dr. Warder bear the same high testimony to its excellence.

It has been almost impossible to get the genuine variety. In our attempts, we have had repeated failures, until, at last, Mr. D. McAvoy politely took up for us two plants, while in bearing, and enclosed them in a letter. The plants lived, and we have been enabled to experiment with them intelligently. We have also seen the genuine in a few other gardens, hundreds of miles apart, during the last two seasons; and everywhere we have seen it, if it had a fair chance, it has done well. Many will, doubtless, discard "Long. worth's Prolific," who have only tried spurious kinds. Our limited experience will not enable us to speak 
so decidedly as some of those we have quoted, yet wt can say we are much pleased with it, and hope it will equal the high expectations excited; so far, it seems to excel any hermaphrodite of our acquaintance in size and productiveness, and is of good flavor. The Pennsylvania Horticultural Society had it on exhibition from the garden of Caleb Cope, Esq., in 185̃3, and speak of it as "very large, roundish obovate, brilliant crimson; seed of the same color, sometimes yellowish, set in rather deep indentations, with rounded intervals; flesh red, flavor fine, quality 'very good,' a variety of great excellence, perfect in its sexual organization, and remarkably productive, a rare circum. stance with staminate varieties of large size." The plant is very vigorous and hardy; large broad leaf, long foot-stalks, setting the fruit well up in large full trusses, productive and sure bearer; ripens at the medium season, and only loses its fine color when over-ripe. We have seen the fruit from four to five inches in circumference.

\section{WALKER'S SEEDLING.}

The last of the six we name above is also one of the new berries, not so extensively proved as yet. The Hon. Samuel Walker, ex-President of the Massachusetts IIorticultural Society, originated and sent it out some two or three years ago, when he politely sent us a 
dozen plants for trial, which trial has been very satis. factory. The society above-named has during the last season renewed its endorsement of it, and Mr. Barry, of Rochester, also approves it there. It is entirely distinct from all other kinds, and is a good honest fruit. In form it resembles the Large Early Scarlet, or more nearly the Crimson Cone, but rather larger than either; in color it is as dark crimson or purple as the Black Prince. A vigorous, hardy, good staminate, of excellent flavor, "best" quality, and productive; of medium season.

\section{MoAVOY'S EXTRA RED.}

This is another of the new Ohio strawberries, orig1nated by Mr. Longworth in his garden, or by his tenant and gardener, Mr. D. McAvoy, at the same time with the Superior, which variety it appears in every respect to equal, except in flavor. The Fruit-Committee in Cincinnati report it as "large, beautiful and very prolific; quality medium, sub-acid not high-flavored." We think it will prove a valuable market fruit: it is very vigorous and hardy; fruit large and handsome, and keeps well. We have seen it exhibited for fortyeight hours, after twenty miles land-carriage, when it remained the brightest and most showy fruit of forty chnice varieties. The Pennsylvania Horticultural Society in 1853 pronounced it "extraordinarily produo 
tive," and quality "good." It is pistillate, and its only faults, as far as we are aware, are its acidity and its lack of high flavor, which we do not consider indispensable for a market fruit.

\section{JENNEY'S SEEDLING.}

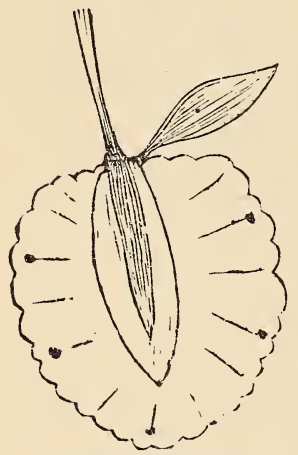

This originated in New Bedford, about the year 1845: is of good size, high flavor; and has been highly recommended by the Massachusetts and other Horticultural Societies. We have successfully cultivated it for four or five years, and think its advantages are, its good fair size, bright handsome JRNNEY'S SEEDLING.

color and form, sprightly rich flavor, lateness of season in bearing, and sound flesh, fitting it for a first-rate market fruit, or for preserving; its defects are, its not being the largest size and only a medium bearer. The plant is vigorous, and blossoms pistillate.

\section{WILSON'S SEEDLING.}

This superior strawberry originated with an excellent Scotch nurseryman, of Albany, John Wilson. It was introduced a year or two before it attracted much notice. In the summer of 1857, I think, $\mathrm{Mr}$ Cummings of the New Yort Ouserver, placed on the 
tables of the New York Horticultural Society, one plant in a pot, which gave a show of fruit far exceeding all we had ever seen. We counted 260 berries on that one plant, and immediately wrote an article calling attention to it. It has now grown into general circulation, and although some complain of its acidity, yet it seems to be steadily gaining favor. It is good size, often large, pointed cone, dark red when fully ripe, solid flesh, good and very productive.

\section{LARGE EARLY SCARLET.}

This has long been the standard staminate. It bears almost every where a tolerable crop with fair treatment. It is early, and, as we see from Mr. Peabody's article in the Appendix, under his treatment has become a perpetual bearer. It is of medium size, handsome oval form, good—rather acid-flavor, and bears carriage to market tolerably well.

Its good qualities are its uniform, although not large productiveness, early season and good flavor; its defects, its want of size and of large productiveness, and its tendency to throw out an overgrowth of runners. It is valuable as an impregnator.

\section{CRIMSON CONE.}

A very bright, handsome, brisk, acid fruit, of medium size, uniformly conical, rich dark crimson, and 4 
quite productive. Its seeds lie deeply imbedded, giving the surface a beautiful rasp-like appearance. Its defects are, its second-rate size and acid flavor. It was always a favorite of MIr. Downing's, who preferred its acid flavor for the table, bringing it to its proper tone by a liberal addition of sugar.

It has supplied the New York market with more fruit the past season, we think, than all other varietien combined.

The plant is very vigorous-blossoms pistillate. IOWA.

The Iowa, or Washington as it is familiarly called in Cincinnati, is a wonderfully productive variety, good size, and well adapted for the market. Its lack of high flavor, and pale color, will prevent its becoming a favorite among amateurs.

\section{TRIOMPHE DE GAND. H.}

This new Belgian variety is very popular. It is very large, bright crimson, flesh firm, sweet, juiəy, very productive and late. Good for the family or market.

\section{GENESEE SEEDLING.}

A large and very handsome fruit. It originated with Messrs. Ellwanger \& Barry. The plant is vigorous, with long stout fuot-stalks, productive for a staminate, 
and of good medium flavor. It seems to be growing in favor for private gardens.

\section{WILLEY.}

This is a great bearer of round, medrum-sized fruit of pleasant, sprightly, although not high flavor. This and Monroe Scarlet are the only strawberries I have ever seen that bear apparently in clusters. It is not unusual for the Willey to produce sixty and seventy berries on a plant, and should never be cultivated in masses. It is solid enough for market, and its main defect is its size and second-rate flavor.

\section{PRINCESS ALICE MAUDE.}

A handsome, long, oval, English fruit, of large size, fair productiveness, and medium flavor. It is unique in appearance, very early, and in the vicinity of Washington City it has become very popular, Professor Page having succeeded in inducing it to adopt the ever-bearing habit. Its main defects are moderate productiveness and want of high flavor. Staminate, and good for market.

\section{BOSTON PINE.}

A good staminate seedling of Mr. Hovey, of Boston, and for our own cultivation we should give it a very early place in our list; but with the mass of cultiva. tors it is not so popular It wants the best clean culti 
vation, with every plant two feet apart from all others, and will bear richer soil than almost any other variety; with such treatment it will produce a good crop of uniformly large, round, handsome fruit of high flavor.

BLACK PRINCE.

A large, handsome, very dark crimson or blackishpurple fruit, of English parentage and pistillate flowers. The plants are vigorous and hardy, quite productive, usually too watery and insipid in flavor, but sometimes we have found it to be of the richest flavor. A few plants are worthy of a place in most private gardens.

BARTLETT. H.

Medium size, good form, crimson, firm, sweet and rich flavor, moderately productive.

SWAINSTONE SEEDLING.

An English staminate of the highest flavor and great beauty, but unfortunately so fickle in its bearing habits as to drive it from all but the amateurs' and a few of the best nurserymen's gardens.

\section{MYATT'S BRITISH QUEEN}

A splendid English variety of the largest size and richest flavor, but unfortunately, in this country, so 
few of the blossoms ordinarily produce fruit, that it is in most places despaired of. It needs the best cultivation, and the olants should be allowed plenty of room for air.

\section{LARGE WHITE BICTON PINE.}

A new English staminate variety, of large handsome fruit, long oval shape, sometimes flattened, of the highest flavor, white color, with a bright blush cheek on one side. It is quite a novelty, and proves to be more productive than was expected. It will find a place in most amateurs' gardens in limited quantities.

\section{BARR'S NEW WHITE}

Is said to be superior to the above, but we have not yet tried it. In Boston it is spoken well of. A friend assures us it is superior to the Bicton Pine.

\section{PROLIFIC HAUTBOY.}

Prolific certainly of runners, so as greatly to injure its value, if it had no other defect; is a very vigorous plant, producing long, oval, purplish, dingy berries of a rich but very peculiar flavor, agreeable to some, but the reverse to others. It is staminate, but hardly desirable.

We might continue this list, and enumerate full one hundred other varieties which we have had an opportunity of personally testing; but we cannot 
name any variety possessing any superior quality, not possessed in an equal or larger degree by some of the best of those we have named; in fact, some of the varieties we have noticed are not equal to other varieties we might name, of our own seedlings and others; and we have only referred to them because they are popular in many parts of the country, and supposed there to be a first-class fruit.

Many of our horticultural friends and nurserymen may be disappointed that we have not referred more extensively to their favorites; in answer we say, we do not suppose them superior to some of those described. If they are, they will soon be extensively proved and noticed. Others, we do not personally know anything about, which are not merely recommended by individual originators, but Horticultural Societies of the highest authority; for instance, the new seedling "Pennsylvania," of Philadelphia, and Scott's Seedling, \&c., of Boston, Hooker's seedling of Rochester, and Lucy Fitch in the West. A seedling that will surpass McAvoy's Superior in average size, productiveness, and good flavor, or Hovey's Seedling , in size and beauty, or Burr's New Pine in flavor, productiveness, and early fruit, and Longworth's Prolific in size, beauty, productiveness and flavor as an herma. phrodite, has got to be an extraordinary fine berry, but there is hope that it may be obtained. 
The fullowing analysis of the strawberry plint (vines) was made by Mr. Bilius, Kirtland, Ohio.

In 116 grains of the ashes of the GARDEN STRAW * BERRY he found:

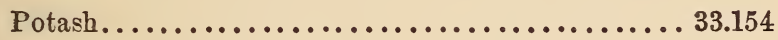

Lime.............................. 26.519

Carbonic Acid........................... 23.008

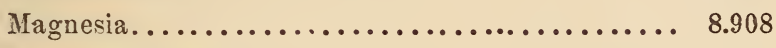

Phosphoric Acid........................ 6.970

Silica.............................. 6.117

Charcoal and Sand........................ 3.103

Soda................................... 2.794

Perphosphate of Iron.................... 1.515

Sulphuric Acid........................ 1.469

Chlorine.............................. $\quad .718$

Organic Matter and Loss................. 1.739

116.000

In the Annual report of the Progress of Chemistry and allied Sciences for 1847 and 1848, we find the following analysis of the Strawberry by THomas RICHARDSON :

THE PLANT.

Potash .............................. 38.65

Lime........................... 12.20

Silica................................ 2.58

Perphosphate of Iron................... 8.65

Magnesia.............................. 5.85

Phosphoric Acid...................... 15.58

Chlorine................................ 1.23 
Soda............................... 9.27

Organic Matter, Loss, \&c.................. 5.99

39 per cent. of Ash.

THE FROTT.

Potash .............................. 21.07

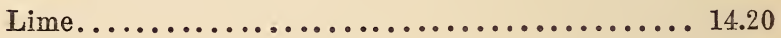

Soda................................27.01

Silica............................... 12.05

Perphosphate Iron..................... 11.15

Phosphoric Acid........................ \& 59

Sulphuric Acid.......................... \$ 15

Chlorine.................................. 2.78

Magnesia............................ Tr

41 per cent. of $\mathrm{Ash}$. $10 \mathrm{v} .00$

The great variation in these analyses is probably mainly owing to the greater age of the vines in one case than the other : perhans nomething is also due to soil and climate.-ED. 


\section{THE RASPBERRY.}

WHEN well-grown, and of the best varieties, this is one of our most wholesome and excellent fruits. It deserves a far more general and better cultivation than is usually given to it; and its free use, succeeding the strawberry, as it does, would doubtless conduce to the general health as well as luxury of the community.

If grown without care, it is often small, hard, and with little good flavor; but when highly cultivated, it is large, melting, and delicious. It will repay the best care, and to very few fruits is this so indispensable as to the raspberry.

A rather moist, cool location, on the north slope of a side-hill, or shade of a fence, is to be chosen; and the soil should be deep and rich. A deep loam is preferable, but other soils by the addition of bog earth or muck can be made to answer the purpose; it should be well broken up, trenched and pulverized to the depth of two feet, then enriched with well-rotted manure, vegetable, if convenient. 
The plants should be shortened ten or twelve inches at the top, and set out very early in the spring, at a distance of three to four feet apart, not too deep, in pure earth, with a good proportion of the roots lying near the surface. Keep them clean, and well staked, with not more than three or four canes in a hill. On gathering of the fruit, cut out all the old decayed canes and leave not more than six, eight, or ten of the strongest ones in a hill to ripen for another season of bearing, one-half of which should be transplanted in the following spring.

On the first of September pinch back the most vigorous shoots, so as to check the flow of sap and ripen the wood.

\section{WINTER PROTECTION.}

The question of winter protection is a difficult and important one. The ordinary custom is to leave them exposed in the garden to the severity of winter, and, as a consequence, the Fastolf, Franconia, and True ANTWERPS, are rendered almost worthless. Even in Kentucky, those choice varieties require winter protection. The easiest way is to bend the canes down and cover them slightly with earth. Some tie them up in a withe of straw, or evergreen boughs, but these are not always sufficient. 
We have sometimes taken up the plants in the fall, and buried them in sand, and on the earliest opening of spring set them out with care, and in this way have raised extraordinary crops; but we have not proved this last process so fully as to incur the responsibility of recommending it. It would require to be very carefully done, so as to preserve all the fibrous roots, together with the advantage of favorable soil, for it to succeed so well.

The raspberry is used in a variety of ways, viz. : for the hand, the table, pies, tarts, jelly, jam, ices, syrups, brandy, wine, and vinegar.

The profits of production are very large; often, in the vicinity of New York, selling for from $\$ 500$ to $\$ 600$ per acre. From Milton, Ulster County, it is said $\$ 10,000$ worth 'is sent every year to New York market. The usual price is about one shilling per pint.

They will continue in bearing some five or six years, but will not be in perfection, ordinarily, until the third year after planting.

We will name but a fer established varieties. Dr. Brincklé, of Philadelphia, and some others, have gained much credit with their fine seedlings, but how extensively they have been proved, or if any of them surpass the Fastolf, Franconia, Antwerp, \&c., we are unable to say. The "Colonel Wilder" and some other seedlings are said to be perfectly hardy; and if that is the 
case, and they prove equal in other respects, they will certainly be a decided acquisition.

\section{FASTOLF.}

This ine variety originated at Fastolf Castle, near Yarmouth, England, where it attained a high reputa-

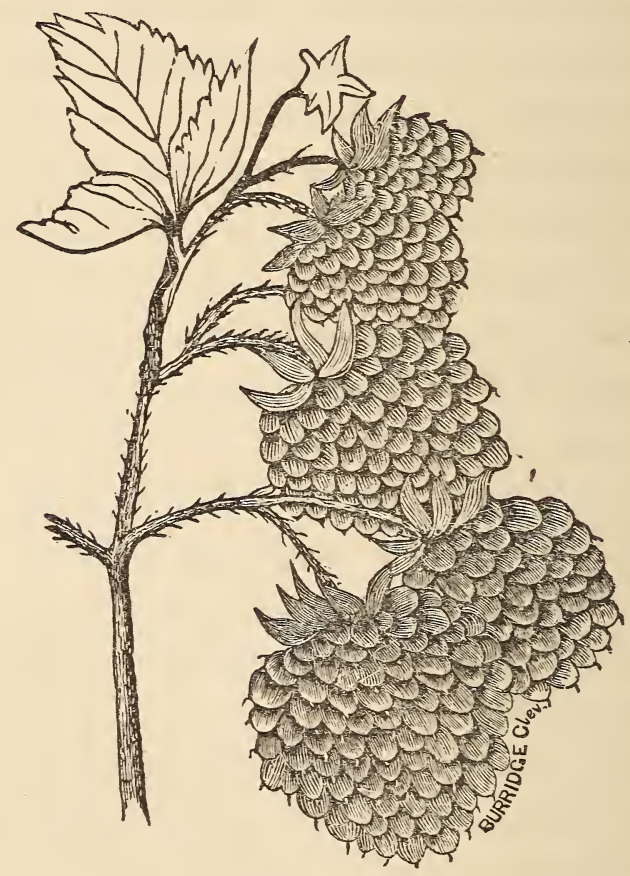

THE FASTOLF.

tion, which it has nobly sustained in this country.

It is not quite so hard for a market fruit as the Ant. werp, but it is rather soft, and of rich high flavor, and 
the fruit is very large, of a bright purplish-red, and is a large bearer. It requires winter protection.

\section{FRATCONI.}

This rine variety was said to be originally from France, but a few knowing ones insist that its advent was nearer home. However that may be, it is a valu. able kind, the most hardy of the large varieties which we refer to; produces most abundant crops of fine fruit, which bears carriage to market well. It is some ten days later than the Antwerps, and requires only slight protection. The fruit resembles the Fastolf, but rather more acid flavor; canes strong and branching, and leaves rather narrow.

\section{RED ANTWERP.}

This variety has long been the standard sort, both in this country and Europe, and is a very fine fruit. So many spurious sorts are now sold under this name, that it is difficult to obtain the genuine, in many places. The Com . mon Red Antwerp is

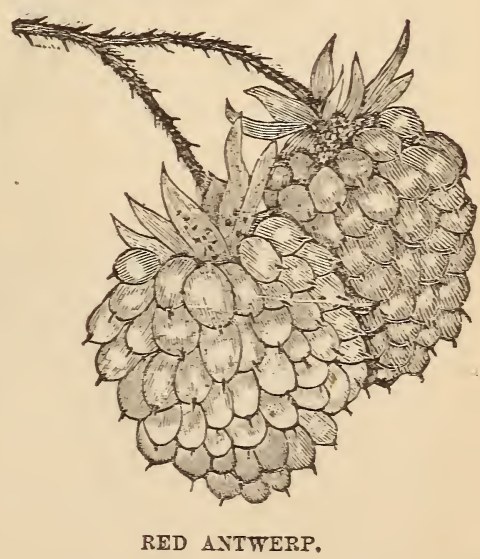


smaller and round; while the true is large, regularly long conical, dull red, with a rich sweet flavor.

The canes are of good strength when well cultivated, and the fruit ripens early in July.

It also requires winter protection.

\section{YELLOW ANTWERP.}

Much resembles the Red Antwerp except in color, and is a very handsome and excellent fruit. Whether Dr. Brincklé's new seedlings, Colonel Wilder, and Orange, will supersede it or not, as Mr. Elliott sug gests, we are unable to say.

\section{KNEVETT'S GIANT}

We have sometimes thought this variety a better bearer than the Red Antwerp, but we do not know as

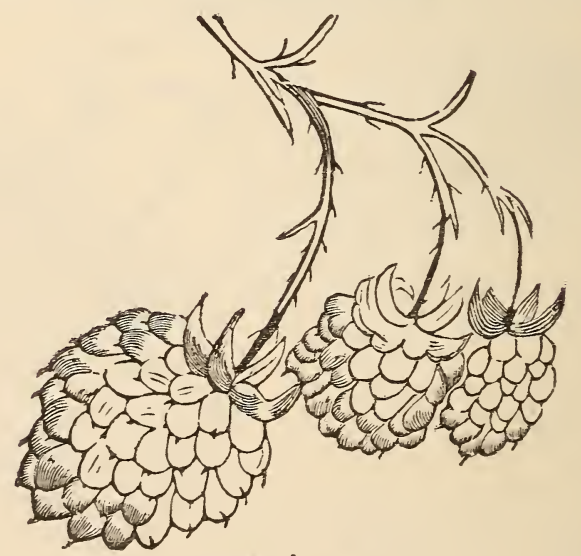

KNEVETT'S GIANT.

it has any superiority other than being more hardy. 
This, however, bears a much larger crop, in consequence of winter protection.

\section{LARGE-FRUITED MONTHLY.}

This is a new variety, that we have had in bearing in our garden some years, and have often gathered a moderate amount of fruit from it in September and October, as well as in the early summer. With good cultivation and thorough pruning, it produces full crops of fruit of the character, but not equal to, the Antwerps.

\section{OHIO EVER-BEARING.}

A variety of the American Black, which has for vears borne us several crops during the season, of large, good fruit, ripening its last crop amidst the snows and frosts of November. Some of our New Jersey markets are realizing on small plots at the rate of from six to eight hundred dollars per acre.

\section{BRINCKLE S ORANGE.}

This is one of the best of Dr. Brincklè's Seedlings. It is large, good orange color, good flavor and very productive. It is becoming quite a favorite. 


\section{THE BLACKBERRY.}

THE production of this fruit has heretofore been mostly confined to the woods and new lands of our country. In our former residence, Palmyra, Western New York, from time immemorial, almost, the marketwomen have made their appearance every two or three days during the season, with wagon-loads of from fifteen to thirty bushels of blackberries, which they sold at the prices of three, four, to five cents per quart. The fruit was often small, hard, and unripe, similar to much that is sold in the New York markets. Some of this fruit is larger and finer than others, and for many years persons have been trying to cultivate and improve upon the best specimens of field blackberries. Our agricultural friends in Massachusetts-particularly the late Captain Lovett, of Beverly_have been among the most enterprising and successful in this direction. The- "Improved High Bush Blackberry" of Captain Lovett has often been noticed with marked favor by the Massachusetts Horticultural Society, as being a long, egg-shaped, shining, black, juicy, and rich fruit, with specimens often an inch and a half long. We have (88) 
seen handsome and excellent fruit of this variety, not only in New England, but also in Western New York, but there is a complaint in some quarters that it has a tendency, like most other kinds, to deteriorate. Many promising varieties from the woods or seedlings, on being cultivated, have scarcely produced a single perfect berry. We personally know of but one decided exception.

\section{THE LAWTON BLACKBERRY,}

Or New Rochelle, which is said to be a chance seedling first picked up by the wayside, and has been most successfully cultivated for many years in the pleasant village of New Rochelle, near New York, where it was discovered to have extraordinary vigor, growth, size and uniform productiveness.

Our attention was first called to it by some baskets of the fruit presented to the Farmers' Club of the American Institute in the city of New York at their regular meetings in August, 1852 and 18503, by Wi1. liam Lawton, Esq., an amateur cultivator, of New Rochelle, who stated that it was familiarly known in the vicinity as the "New Rochelle Blackberry."

The fruit was found to be of great size, uniformly so, sixty to seventy of the berries filling a quart mea. sure-very few seeds, light melting pulp, and of a delicious flavor. 


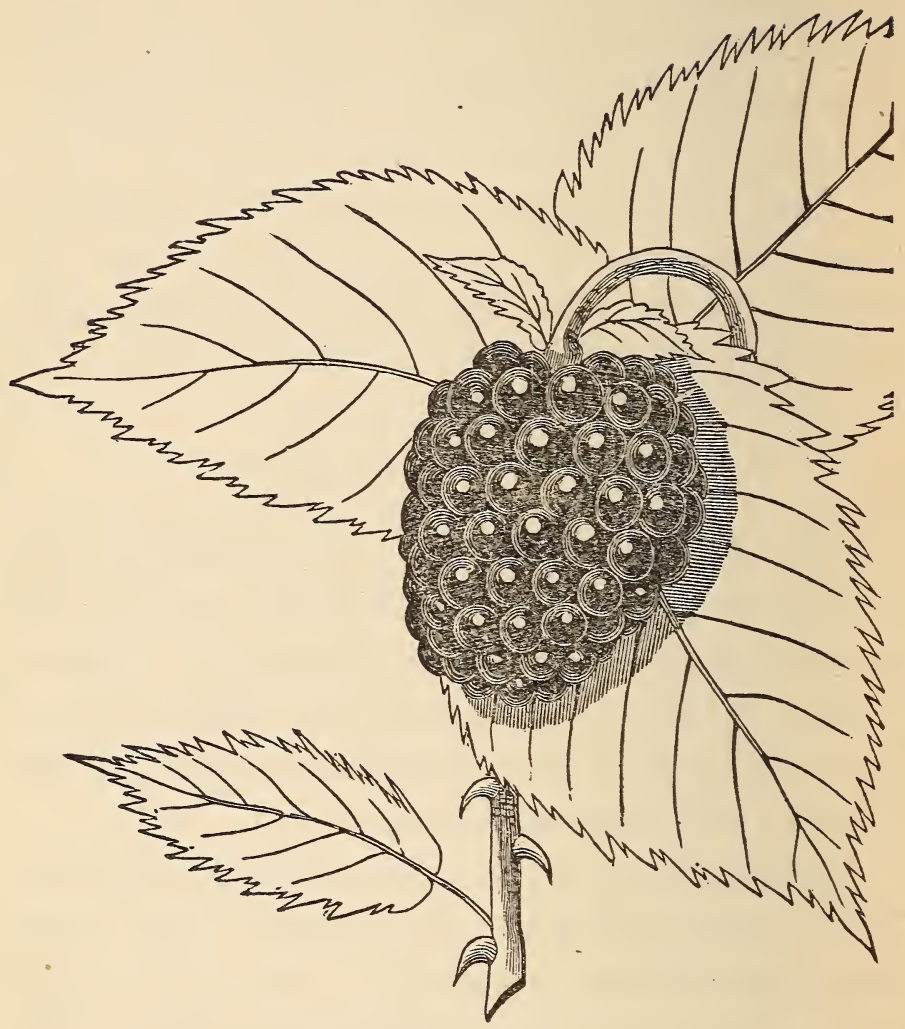

THE LAWTON BLACKBERRY.

It was well known that not only in New Rochelle, but also in Morrisania, and the open lands of Long Island were filled with seedlings of greater or less excellence, but this variety so far surpassed all others known to the Club as to excite their admiration. On account of the liability $o^{\mathfrak{c}}$ the numerous other wild 
varieties in New Rochelle becoming confounded with this, the Club resolved to name it, distinctively, "The Lawton Blackberry," in honor of the gentleman introducing it to them.

We have had frequent opportunities of giving this variety a personal examination in various places and under different treatment, and particularly in the grounds of Mr. Lawton, where there are some three acres in bearing.

\section{THE CHARACTERISTICS}

Of it are a hardy vigorous growth, the canes are often an inch in diameter, and eight to twelve feet long, covered with laterals well loaded with fruit; so that a single stalk will produce from four to six and even eight quarts, and the canes are uniformly full of large perfect fruit in different exposures and locations.

The Fruit is of regular, large size, oval shape, handsome, and superior flavor, so that our best pomologists, after a trial of several years, do not hesitate to pronounce it "the greatest acquisition." It is quite certain it has not deteriorated in the last eight or ten years, and it proves to be entirely hardy

\section{CULTIVATION.}

The blackberry rejoices in a moist, loamy soil, but will grow well in higher exposures, and is rather benefited by a little shade and a cool northern aspect. 
When thus favored, it will prolong its period of bearing from four to six weeks. Usual good garden soil is fuvorable for the blackberry, and it will bear being mante pretty rich with manures after the first year and especially with muck or woods'-mould. It should be transplanted as early in the spring as possible, or in the fall, and especial care should be taken of its fibrous roots and its whole general culture the first year, and then it will grow, produce fruit, and propagate itself rapidly.

The canes which come up one season will bear fruit the next and then die in the autumn, and the dead branches must be carefully removed early every spring, in order to make room for the new ones to take their place, and this beautiful process of reproduction thus goes on; so that a single plant set out in a good free soil will send up two, three, or four plants, and those will increase to a score or more the following season if carefully pruned and kept clean.

The ends of the canes should be shortened about one quarter early in the spring, when the old decayed ones are removed, and if the laterals are too long clip them also. They usually require no support.

TRANSPLANTING.

Particular care, we think, is needed in transplanting the biackberry. It should not be attempted late in the spring, otherwise a great share of the plants will hardly. 
survive the process. Mulching and watering are often useful and even necessary when transplanting.

It is well to set the plants four or five feet apart in rows that are eight to ten feet distant, and they will soon cover the ground, and thus 500 plants will set an acre. Some large growers in the vicinity of New York have readily contracted their entire crop for the season at 25 cents to $37 \frac{1}{2}$ cents per quart. We have given a large space to this variety, not only because it is new, but because we believe it to be worthy of extensive cultivation by the public, both as amateurs and for the market.

\section{NEEDHAM'S IMPROVED WHITE BLACKBERRY}

Is a great bearer, not white, but with a blush cheek, and not of good quality or size when compared with the Lawton; sometimes it fails, but we are certified tc instances of single canes producing eight, ten, and even eleven quarts of fruit, such as it is.

We have seen the wild white blackberry growing in the woods, on the southern shore of Lake Ontario, in the town of Ontario, Wayne County, but on cultrvating them they have failed to produce a single perfect berry. This has been the case also with the best specimens of black ones grown in the vicinity. 


\section{THE CRANBERRY.}

THE culture of the American Cranberry has become an object of much interest and importance. It grows freely and produces its fruit readily in any damp situation. Pare off the surface of a swamp or bog-meadow, then cover the surface with a few inches of sand, set out the plants 12 or 18 inches apart, keep them clean, and in two or three years they will cover the surface of the ground, and produce, say 50 bushels the first year, 100 the second, and after that a regular crop of 150 to 400 bushels per acre.

They can be raised upon poor uplands by first cover. ing the surface with sand; set them out and keep the ground free from weeds. Planting can be done from March until middle of May, or from September until the ground freezes. The black cranberry has formerly been considered the best variety, but some new seedlings exhibited the past season promise decidedly to surpass it.

A new work just issued from the prolific agricultural publication house of C. M. Saxton \& Co., New York, by the Rev. B. Eastwood "On the Cranberry," ren. ders a more extended notice unnecessary in this place. 


\section{THE CURRANT.}

THis is one of the most valuable of all our smail fruits. It can be used to such advantage in a variety of ways, whether in a green or ripe state, and it is so easily grown, that it is indispensable in every small garden.

It is a native of Great Britain, and therefore perfectly hardy. In a green state it is used in pies, tarts, \&c., stewed like gooseberries. When ripe, it is much used as a table fruit, with plenty of sugar; but it is almost universally used in a jelly that is both delicious and wholesome. It also makes an excellent wine, at a cost of not more than two or three shillings a gallon. The Black Currant is chiefly used in a jam or jelly. Currants ripen in midsummer, and if protected from the sun will remain on the bushes until October.

This fruit is very easily cultivated, and it will grow and bear in almost any fair soil; fresh maiden earth is best for treatment. The usual way is to allow the suckers to spring up around the original plant, until it has becorne a matted clump of bushes, but this is a bad practice every way. The suckers uniformiy pro- 
duce poor and small fruit, and should never be permitted to grow.

The best way of propagating the currant is to cut off in the early spring; before the buds swell, the growth of the last year, close to the old wood; make the cuttings one foot long; remove all the eyes except some three or four at the top of the cutting, to prevent suckers; then place it compactly in good sandy soil to half its depth, or six inches, and by good care in one year it will be sufficiently established for transplanting. In new, rare varieties, it can be more rapidly increased by layering, where the first branches have been allowed to grow near the surface of the earth. It should always be cultivated in the form of small bush trees, and by a skilful hand can be easily made to assume a handsome pyramidal or espalier form. All superfluous wood should be carefully pruned out every winter, and the plant invigorated with rich manure in the spring. The currant and gooseberry can hardly be over-fed. Each bush should be renewed every six or eight years, as young vigorous plants of most fruits produce the largest and best specimens. It will bear very well partially shaded by trees or shrubbery, yet the fruit will be the richest and best flavored with plenty of air and sun, and therefore a southern aspect is desirable. 


\section{VARIETIES.}

Black Naples and Bang-up are the largest and best Black Currants, of excellent flavor, and bear large clusters of fruit, often five-eighths of an inch in diameter. They are also productive. The Black English is quite inferior.

The White and Red Dutch are our most popular varieties. They are large, good flavor and productive. I'he white is the mildest. They are decidedly better than the common currant.

The White and Red Grape do not vary but a little from the above.

Cherry Currant.-The largest of all red currants ; quite acid; short clusters; moderate bearer; color, dark-red; strong grower; thick, dark-green foliage; new, from Italy. Sometimes seven-eighths of an inch in diameter.

MaY's ViCtoria, or Houghton Castle; large and very long bunches; late, and rather acid; moderate bearer; plant vigorous.

KNIGHT's SwEET RED, chiefly valuable for its mild pleasant flavor, similar in quality to the White Dutch, and productive. 
Largest White Provence, the largest White Currant, often full five-eighths of an inch in diameter; short bunches, and quite acid; a good bearer; quite attractive; new, from France. We are pleased with it in our own garden.

\section{LA VERSAILLES.}

This is one of the new French currants, and is a decided acquisition. It is as large, handsome, productive and hardy as the Cherry Currant, but decideoily superior to it in agreeable flavor. 


\section{THE GOOSEBERRY.}

No fruit is easier of propagation than the goose. berry, and it should find its place in every garden.

It should be protected from suckers, like the currant, and like that it loves a fresh, deep, rich, moist soil of a soft, loamy texture; it can scarcely be too much enriched with cooling manures. The north side of an open fence or hedge will do well for it, but it should not be placed under the shade of trees; open ground is far better. It should be so carefully and thoroughly pruned as to admit the air and light freely, and it is well to train it up into little upright bushes or small trees. Summer as well as winter pruning is often necessary to admit sun and air.

The English varieties are much subject to mildew in this country. Mr. William Newcomb, of Pittstown, N. Y., a very successful horticulturist, wrote me that he always in the spring placed three inches of hogmanure under every bush, and raised the best English varieties in that way in the greatest abundance and 
perfection, without its being affected in the least by the mildew.

Mr. D. Haines, near Elizabethtown, N. J., informs me that he cultivates Woodward's Whitesmith most successfully by removing a few inches of the surfaceearth, every spring, under every bush, and filling the space with salt hay, which he covers with the earth; thus affording protection from drought, and perfectly exempting the fruit from mildew. Others find a remedy in sprinkling ashes on the bushes when the dew is on. The ashes also benefit the plant. Any good mulch of tan bark, saw-dust, \&c., of three inches deep, would answer nearly the same purpose as salt hay. Sprinkling the bushes in the spring freely with soap-suds also has a good effect on their growth, and often protects them from mildew. The bushes should be transplanted in April or late in October or November, and pruned back and set at a distance of about three feet, like the currant. If any large fruit is wanted, the fruit must be thinned out. The Encyclopoedia of Gardening says of the farnous growers in Lancashire, England, who produce the largest fruit in the world: "To effect this increased size, every stimulant is applied that their ingenuity can suggest; they not only annually manure the soil richly, but also surround the plants with trenches of manure for the extremities of the roots to strike into, and form around the stem of each plant a 
basin, to be mulched, or manured, or watered, as may be necessary.

"They also practice what they term suckling their prize fruit. By preparing a very rich, cool soil, and by watering, and by the use of liquid manure, shading and thinning, the large fruit of the prize cultivator is 1 roduced. Not content with watering at root and over the top, the Lancashire connoisseur, when he is growing for exhibition, places a small saucer of water under each gooseberry, only three or four of which he leaves on a tree; this he technically calls suckling."

The gooseberry tree needs to be kept constantly in a vigorous condition, and then it will produce an abundance of good fruit.

It should be propagated from cuttings of the rood of the present year, prepared and set out early in September, and transplanted in October of next year, or very early in the following spring; and should be pruned in June and November, and renewed every five or six years. The short stout growth from the fruit stem makes better bushes than longer cuttings from the thrifty suckers.

The fruit is well adapted for pies and tarts when in a green state, and the best varieties when well grown and ripe are very excellent and acceptable for the table or hand Says Mr Downing: "As a luxury for the poor, Mr. Loudon considers this the most valuable 
of all fruits, since it can be grown in less space, in more unfavorable circumstances, and brought sooner into bearing than any other."

Books and catalogues are filled with the longest lists of names of different kinds of the gooseberry, but afte: experimenting with many of them for years, and observing them under various circumstances, we are prepared to narrow our list down to a very few kinds, -as we have studied to do with the other fruitswhich we think combine the size, flavor, and productiveness of all, at least for ordinary cultivation.

CROMPTON'S SHEBA QUEEN.

This is the largest and best flavored of all the English varieties we have seen. Our attention was attracted to it some years since by the favorable reports and first premium of the Albany Horticultural Society, through the accurate chairman of its Fruit Committee, Dr. Herman L. Wendell, who says of it, "This is decidedly the richest and most delicious, as well as one of the most beautiful berries we have. It is larger in size than any of tne others; obovate form; white, clear color; very pleasant, rich, and luscious in its flavor, and erect in its growth. It requires a deep, rich, and 
well-drained, as well as cool soil." In other locatic ns it sustains the same high character there given of it, and we have found it decidedly the best in our own garden.

\section{WOODWARD'S WHITESMITH.}

This is another large, beautiful, and excellent English variety-very productive, and is usually over one inch in length. The color is white, and tree of erect habit.

Roaring Lion and Crown Bob Warrington are also large, good varieties of red color.

Golden Drop and Yellow Lion are fine yellow kinds.

Green Laurel, Conquering Hero, and Green Willow, green varieties.

We might name a great number of varieties nearly as good, but do not know that any benefit could be derived from it.

\section{HOUGHTON'S SEEDLING.}

An American seedling of very vigorous habit, great bearer, and said never to mildew. It is of pale red color, rather under medium size; of good, rich flavor, and well worthy of cultivation.

We have also cultivated for some years an American seedling variety resembling Houghton's Seedling in every respect, except being of larger size, and greenish. white color. It is very valuable. 


\section{TII E GRAPE.}

IT has orten been asserted-we know not with how much of truth-that in the vine districts of France, lung diseases are unknown; but this we do now, that the free use of well-grown and well-ripened grapes would be decidedly beneficial to the general health. The cultivation of this excellent fruit embraces a very wide range. In the first place, there is the very nice process of raising hot-house grapes: next, the cold vinery, which is simple and easy to be practised; next, vineyard cultivation: but it will not be expected of us, in this brief notice, to more than refer to the common mode of out-door garden culture. The grape is easily and cheaply raised, but good cultivation is altogether the best economy. It is easily propagated from cuttings. We have found it the best way to prune oft our cuttings early in February, two feet in length, bury them in a bundle four or six inches deep in the ground immediately, and for this purpose we choose the warmest weather in the month. 
Let them be in the ground till the warm weather in the fore part of May: we then take them up and plant them in a sloping position, in a somewhat shaded situation, leaving the upper bud a few inches above ground. In this way almost every cutting will surely grow, and after a year or two, should be carefully transplanted into the vine border.

The preparation of this vine border is an important process in grape culture in private gardens. It should be made from four to six feet wide, and two to three feet deep, and be composed of a liberal mixture of limestone, or old plaster or mortar, bones, leatherparings, hair, ashes, and strong, well-rotted manure, well mixed with the soil.

A calcareous soil or gravelly loam is best for the grape, and should be well drained and warm. "The essence," says Downing, "of all that can be said in grape culture respecting soil, is that it be dry, light, deep, rich." It is somewhat difficult in wet clay lands to raise good grapes, unless the vine border is carefully prepared. Soap-suds and wash from the house is favorable for the grape, and we have known some plants succeed well that were placed immediately under the spout of the sink. For vineyard culture, the nearer the process approximates to the one described above by trenching and enriching, the better.

Every plant should be thcroughly pruned down to $5 *$ 
two or three leading shoots; and after these cover the trellis or stakes as extensively as you wish, then the rule in pruning is, every year from December to first of February, fearlessly to cut back all of the last year's growth, so far as to leave only two eyes. It is also desirable, after the grapes are beginning to fill in June, to pinch back the terminal bud of every branch, and thus check its growth, and throw back its sap, to ripen the fruit and mature the wood. By pinching back, we mean, to pinch off with the thumb-nail and fore-finger the end of every bearing branch, and we then cut out all the superfluous little shoots and suckers.

The vine is composed the greater part of potash, lime, and carbonic acid, and therefore a frequent application of ashes, lime, and soap-suds is beneficial. It has been asserted that tartaric acid is a valuable specific for the fruit, but of this we have no personal knowledge.

The grape should always be grown in the warmest and most sheltered situation, so that the fruit may ripen well before frost. The south side of a house, or snuthern slope of a side-hill, should be chosen.

In some places the mildew is troublesome to the grape, but sulphur sprinkled liberally on its first appearance will usually check it at once. There is also a kind of snail slug which often destroys the leaves in a few weeks. These can easily be destroyed by shower 
ing the vines two or three times with strong soap-suds from the wash.

Our nurserymen have many kinds of the grape on their lists for open-air cultivation, but we are not quite sure that the Isabella and Catawba do not comprise substantially the good qualities of all The only complaint against them seems to be, they will not in all situations and all seasons at the North ripen before the frost.

The Isabella is the well-known and most popular grape North. It is a most vigorous grower, hardy, an immense bearer, large size, black oval, and when ripe, juicy, sweet, musky, and rich. Ripens well as far north as forty-three degrees of latitude.

The CATAwBA does not always ripen well so far north as forty.three degrees. Otherwise it would rival the Isabella. It has large berries, copper-colored, with a fresh bloom, flesh a little pulpy; juicy, sweet, aromatic, musky, and rich, productive and hardy. It requires a warm soil and sheltered location north of New York to perfect its fruit, and then it is truly delicious.

The Clinton is two weeks earlier than the Isabella but it is not near sc large or good. 
We are in great want of a new seedling grape equal or superior to the Isabella and Catawba, and decidedly two or three weeks earlier. We often have such an. nounced, but they do not always prove satisfactory.

The Concord is a large, handsome grape, newly originated by Mr. Bull, of Concord. It resembles the Isabella in appearance, is alsout two weeks earlier, and on that account an acquisition; is of good flavor, although not equal, we think, to that grape in flavor. It is a little shade foxy.

The Diana is a pleasant new grape, resembling the Catawba in color and flavor, of smaller size and some two or three weeks earlier.

The Black Madeira is a small pleasant wine grape. Farther south, the Bland, Ohio, Herbemont's, Norton's, White Scuppemong, Warren, \&c., are popular. The Delaware, is now the favorite grape for earliness, hardiness, rich, sweet vinous flavor, unsurpassed both for the table and for wine.

The Anna, Rebecca, Iowa, Crevelling, and other new varieties, promise well.

Hartford Prolific is a very hardy, early good variety 


\section{Appendix.}





\section{A P P E N D I X.}

APPENDIX A.

\section{THE STRAWBERRY AND ITS CULTURF}

\section{BY CHARLES A. PEABODY, OF COLUMBUS, GEO.}

TнAт eminent horticulturists are liable to be mistaken in their views of criture, as well as of the origin and history of plants, as any other class of men, we have ample proof in the conflicting opinions of the nature and culture of the strawberry. Downing says: "The strawberry is the most delicious and most wholesome of all berries, and the most universally cultivated in all gardens of a northern climate." Again he says: "The strawberry properly belongs to cold climates, and though well known, is of comparatively litle value in the south of Europe." With this high authority, the horticulturists of the South never dreamed of cultivating the strawberry to any extent, although the woods and fields were covered with the wild fruit. It was a knowledge of the fact that the wild strawberry 
grew all around me, that induced me tc try strawberry culture at the South. I do not believe there is a plant in nature that so easily adapts itself tc soil, situation, and climate, as the strawberry. In many of its homes, however, it produces little or no fruit, spreading itself rapidly by its runners.

Now, as there are two ways of propagating the strawberry, one by its seeds and the other by its runners, the question is, which method do we prefer? If we were going to introduce the strawberry-leaf for a tea, for which it makes a good substitute, common sense would dictate to us to cultivate for runners, and stop the fruiting, or perfecting the seed, as the fruit is nothing more than the receptacle for the seed; and if, on the other hand, we wish seeds or fruit, we must cultivate for that purpose alone, and stop the runners.

Intelligent experimental cultivators have long since discovered that plants have a specific food for their wood, leaves, and fruit. Physiologists know full well that it takes different substances to form the bones, flesh, and muscles of animals; and, profiting by these hints in nature, I would feed for fruit instead of vines. Before planting out the vines, the cultivator should understand the sexual character of the plants, as upon a proper knowledge of this fact will depend his whole success in culture. That plants are staminate and pistillate, or male and female, no intelligent cultivator will 
now presume to deny. But in the strawberry there are three varieties - the perfect male, the perfect female, and the hermaphrodite. The perfect pistillate, or female, is the most productive of the three, when im. pregnated by one of the other kinds. The perfect staminate, or male, produces no fruit, making a great show of flowers, and sending out innumerable runners which will soon take possession of the whole bed. The hermaphrodite produces fruit, but not in so great abundance as the pistillate, and answers the purpose of an impregnator equally as well as the purely staminate. These three varieties of flowers are represented by Figs. 1,2 , and 3 , page 51 .

Fig. 1 is from an hermaphrodite plant, which blooms and impregnates itself. The stamens, marked $a$, are full of a fine pollen, or yellow powder, which falling on the end of the unopened calyx of the buds, beluw the flower, or around it, on the pistillate plants, is carried by an unseen agency direct to the pistil, impregnating and setting the fruit. This variety is the Early Scarlet, a continuous bloomer with my culture, and the best impregnator for the ever-bearing Hovey Seedling I have ever met.

Fig. 2 is the sterile staminate, or male plant, never producing fruit under any circumstances whatever. It will be observed the flower is larger and more showy than the others. It deceives many an inexperienced 
cultivator with its false promises of fruit. The flower of the pure male may be easily known by its large anthers and stamens, as marked $a, b$, in Fig. 2 .

Fig. 3 is the pistillate or female blossom. It will be observed that there are no stamens around the pistil, as $b$, but nearly every bud will produce a berry if impregnated by one of the staminate or hermaphrodite plants. Of this variety is the Hovey Seedling, which, as far as my experience goes, is the best strawberry ever yet cultivated, North or South.

Before proceeding to the method of culture, I will give my views of the time of impregnation, being fully satisfied that the generally received opinion that the strawberry is impregnated after the petals expand, is entirely erroneous. I have long since observed that the first strawberry blossoms never produce fruit. The staminate varieties, or rather the hermaphrodite, open from two to ten blossoms, which must shed their pollen on the ends of the unopened calyx of the young buds below, or fall on the ends of the unopened pistillate buds, and immediately cause impregnation.

The pollen of flowers is one of the most volatile substances in nature. That of the strawberry, viewed through a microscope, is a hairy substance, which, upon ripening, bursts and floats off on the least breath of air. The point of the unopened calyx contains a glutinous matter, which catches and holds 
this hairy pollen, and the work of impregnation is done; and when the calyx opens, and the petals expand, the young strawberry may be seen perfectly formed. From this will be seen the importance of the pistillate and staminate varieties blooming together. I would always prefer the pistillate plant for a large fruit crop; for, if properly impregnated, nearly every bud will be a berry. Thousands of blossoms will be found in the beds to correspond with Figures 2 and 3. Fig. 2, let it be recollected, is a staminate or male flower, and Fig. 3 an impregnated pistillate or female flower, neither of which, by itself, can ever make fruit.

Having now explained the sexual character of the plant, and the time of impregnation, I will proceed to the culture. As I have before stated, were I to cultivate for vines alone, I would stimulate the plants by the most active fertilizers; but if fruit be the object, the luxuriance of the vine must be curtailed, and that food only known as the special food of the fruit given.

Now as to soils. There are as many opinions as cul tivators, from the fact that the strawberry adapts itself to almost any kind of soil. But the soil which I have found to suit them best, is a sandy loam. I would prefer new land for the beds, with a stream of water running through them, as water, keing an indispensable requisite, should be in the vicinity.

It is now well known throughout the Southern 
States that for many years I have cultivated the strawberry extensively, and have had from my beds a constant succession of fruit six months in the year, and frequently have it ten. While I am now writing, (December 24), one of my beds, of an acre, is loaded with ripe fruit, specimens of which I have sent to New Orleans, Montgomery, Savannah, Charleston, Mobile, and New York. This bed has scarcely produced a runner the past season. The causes of this will be found in my method of culture. I have said that I prefer a sandy soil and new land. My grounds are on what are called "piney woodlands," hill and valley, with never-failing streams meandering through them. I have taken the grounds bordering on the streams, ploughed them deep, and laid them off in rows, two feet apart, and planted as indicated in the annexed diagram:-

$\begin{array}{ccccccccl}\circ & 0 & \circ & 0 & 0 & 0 & 0 & 0 & \text { Early Scarler. } \\ * & * & * & * & * & * & * & * & \text { Hovey's. } \\ * & * & * & * & * & * & * & * & \text { Hovey's. } \\ * & * & * & * & * & * & * & * & \text { Hovey's. } \\ * & * & * & * & * & * & * & * & \text { Hovey's. } \\ * & * & * & * & * & * & * & * & \text { Hovey's. } \\ * & * & * & * & * & * & * & * & \text { Horey's. } \\ * & * & * & * & * & * & * & * & \text { Hovey's. } \\ 0 & \circ & \circ & 0 & 0 & \circ & \circ & \circ & \text { Early Scarlet. }\end{array}$

I plant the pistillate for fruit, and the hermaphrodite for impregnators; and the only two which I lave 
found to bloom and fruit together the whole season are the Hovey Seedling and Large Early Scarlet. Ross Phœenix, Burr's New Pine, and a seedling of my own, not yet fully tested, I have also caused to bear continuously. I plant seven rows of the pistillate, and one row of the hermaphrodite, two feet apart each way. The first season I let the runners fill the ground; in the fall, go through the grounds with hoes, thinning out to eight or ten inches, leaving the vines to decay just where they are cut up. I then cover the whole bed with partially decomposed leaves from the woods or swamps. The winter rains beat down the leaves, the fruit-germ finds its way through them, and the first mild weather of spring the blossoms appear.

I have before spoken of the volatile nature of the pollen. In very dry weather the particles float off on the winds, and much is lost to the buds below; hence the importance of watering freely when in bloom. Free applications of water will set the whole bed with fruit, which will require continuous watering to swell nd ripen it. A strawberry bed may be moist, the plants in fine condition, and yet one good shower will make a difference of one-third in the quantity of fruit picked the day after. Consequently, in dry seasons, artificial watering must be resorted to, and no labor will pay better

I never use animal manure of any kind-nothing 
but the leaf-mould, and an occasional sprinisling of wood-ashes. The leaf-mould keeps the ground cool and inoist, as well as the fruit clean, and does not stimulate the vines to runners. The potash and acids contained in it are just what the fruit wants. Should the vires be disposed to spread, keep the runners down by constant pinching off, and clear out the grass and weeds with the hoe. A few years of this culture will check their disposition to run, and encourage them to fruit. The bed, once thus formed and cultivated, will, to my certain knowledge, continue productive twelve years, and, I have reason to believe, as much longer as the culture is continued. Should the vines have taken possession of the ground, in spite of the efforts to keep the runners down, we go through in the fall with the hoe, thinning out the plants to ten or twelve inches, leaving every cut-up rine to decay on the ground where it grew; we then cover with the decaying leares. When the plants begin to bloom in the spring; a top-dressing of wood-ashes will be found beneficial. I have tried strawberry culture with the plough, which will make a greater quantity of vines, but will give only one crop of fruit. It is generally remarked that the wild strawberry is finer flavored than the cultivated; but with this treatment the latter retains all the original flaror.

It has been recommended by some cultivators to 
irrigate the strawberry grounds by letting water on the vines; but the strawberry, cultivated after the manner described, can bear as great a drought as any other plant. It is not the vines and leaves that want the water, but the flowers and fruit; and the water must come in the form of rain, through the clouds, from an engine, or a common watering-pot.

I have noticed quite a contest going on among horticulturists as to the possibility of strawberries changing their sexual character by cultivation. Without taking part in the controversy, I must state that I would as soon think of high feed turning a cow to a bull, as to change the pistillate character of Hovey's Seedling by any method of cultivation. I have cultirated the strawberry under every aspect; with high manuring, and without manure; in new lands, and on old lands; have had the vines stand from twelve to eighteen inches high, and in meek submission to hug the ground; yet I have never found the least change in the blossom. A perfect pistillate or staminate flower, first blooming so from seed, will never bloom any other way. Cultivators are often deceived about their plants, from the fact that they frequently find varieties in the beds which they did not plant; but these spring from seed. The strawberry springs from seed w:th astonishing rapidity. Since my beds were started, the whole country around me is covered with straw 
berry-plants from the seed dropped by birds. These I find running into all varieties-pistillate, staminate, and hermaphrodite-most of them worthless, but some with good fruit.

The proper time for transplanting the strawberry at the South, is as soon in the fall as the weather is cool and moist enough. Here, this may be continued until spring. Plants are easily transported great distances in the winter. I have sent them 2,000 miles with safety. It will be observed by the diagram, that I plant the staminate every eighth row. Some cultiva. tors mix in the rows; but I prefer to keep them separate and distinct, as they are more easily distinguished, and kept better in their places.

Now, if the cultivator would know the secret of my having strawberries six, eight, and even ten months in the year, in the hot climate of Georgia and Alabama, it is this: proper location, vegetable manures, shade to the ground, without exhaustion, and water to the bloom and fruit.

One reason why so many fail in garden culture with the strawberry is, that the beds are surrounded by trees and shrubbery, which may produce one crop of fruit in the spring, but rarely more than that, unless it should prove a very wet season. The strawberry-bed, whether in the garden or the field, should have no tree, plant, or shrub near enough to it to take the moisture 
from the earth. The plants require all the moisture from the atmosphere and the earth around them.

Whether the strawberry was originally found in cold climates, or not, I find they readily adapt themselves to any climate, and very soon become indigenous: I doubt whether there is a State in this Union that can. not produce the strawberry months, instead of weeks, i $\eta$ the year, with proper culture. And when we take into consideration the ease and simplicity of its culture, its continued bearing and productiveness, its exemption from all insect depredations, its delicious flavor and healthy influence upon the system, it ranks first in importance among the fruits of the earth.

\section{APPENDIX B.}

[From Downing's Horticulturist.]

TWO EXPERINENTS MADE TO TEST MR. LONGWORTH'S STRAWBERRY THEORY.

TAKING Hovey's Seedling as a subject, I procured a beli-glass, and placed it over an entire plant which had not bloomed. The flowers expanded well under the glass, but did not produce one berry. The plant was frequently agitated to put the pollen in motion, if there was any. 
I also introduced under a glass some blossom buds before they had blown. These, as they successively expanded, showed no signs of swelling. I impreg. nated, at different times, two of the blossoms by hand, applying the pollen from another plant with a camel's hair pencil. These two set their fruit perfectly. The pistils of the other blossoms soon turned to a dark color. These experiments were made at the north side of a picket fence, where the plants were screened from the full effects of the sun, otherwise the heat under the glasses would have been too great.

These experiments prove, to my mind, very conclusively, that Hovey's Seedling will not bear any fruit unless impregnated by some staminate variety. And the same may be said of other varieties in which the stamens are obsolete. I have had some plants of the Hudson Bay for three years, in a position where they cannot very easily be impregnated by other kinds, during which time they have not borne one berry, while other plants of the same variety, exposed, have been productive. A difference in the formation of the flowers on different plants is not confined to cultivated kinds, but may be seen in those growing wild in the fields, the pistillate plants of which I have often sxamined with a magnifying-glass, to see if I could discover any pollen, but have never been able to find it; I am forced, therefore, to believe that pistillate planis, Loth 
wld and cultivated, are absolutely devoia of pollen, and cannot, therefore, produce any fruit except when impregnated by others.

I am also convinced, from observation and theory that one kind will never change to the other by offsets, the runner bearing the same relation to the plant producing it as a tree grown from a bud does to the tree from which it was taken. It may, then, be asked, How does it happen that there are pistillate and staminate plants of the same variety? I answer, It is not the fact, unless they have sprung from seed, or the plants have been taken from the fields in a wild state.

That pistillate plants are surer and better bearers than staminate plants, is, I think, generally true, (provided, of course, that they are impregnated). And it would seem reasonable to infer that when but one of the sexual organs is complete, the other will have more strength. Plants, therefore, that are perfect in both organs, require a higher state of cultivatiun. There is, however, a wide difference in the productiveness of different kinds that are perfect in both organs, some being much more liable to blast than others.

G. W. Huntsman.

Flushing, L. I. July 14, 1846. 


\section{APPENDIX C.}

Cincinnati, Ohio, Aug. 14, 1854.

Mr. R. G. PARdeE:

DeAr Sir:-By this mail I send you a grape pamphlet, containing an article written by me on the strawberry. I will, in a day or two, send you a Report of our Strawberry Committee, written by Dr. Warder, on Mr. Meehan's doctrine of changing a pistillate to a staminate plant. Mr. Meehan finds plants that he took from what was called a bed of Hovey's Seedling, and had nearly all proved staminates or hermaphrodites. Dr. Warder and Mr. Heath, of our city, saw his plants, and found about one Horey to the hundred. The Hovey is so strongly marked that our children can distinguish the plant from all others. Mr. Meehan never heard of a pistillate plant till he came to America. I sent some of our seedlings to the President of . the London Horticultural Society last winter, and among them pistillates. He replied that he was not aware that there were plants that would not bear fruit without impregnation, and suggested that the failure to bear, he presumed, was from frost. He promised to investigate the subject. Mr. Huntsman, of Flushing, Long Island, is a botanist, and has given great atten. 
tion to the cultivation and sexes of the plant. From the stem and leaf he can designate some fifty varieties that he has had in cultivation. I would recommend you to get his views. It is singular that after public attention has been brought to the question for twenty years or more, even botanists and horticultural editors deny the doctrine. If generally understood, the discovery of the ignorant market-gardener is worth millions of dollars. After I had made the discovery, from a chance observation of a son of Mr. Abergust, I was at the gardens of persons near the city of Philadelphia, where Mr. Abergust resided, prior to his emoval to Cincinnati, and named the matter to them. "Oh," said they, "we now understand it. He lived near us, and from the same space of ground raised five times as much fruit as we could, and larger. Every fall he thinned out his plants, and threw them in the road; we gathered them, and planted them in our gardens, and they never bore a single fruit. He threw out staminates only, and to deceive them. The son of Mr. Abergust was in my garden a few days before my plants were in blossom, and observed, "Your strawberries bear a bad crop." I observed, such was the fact. He added, "They are all males." I replied, "That is all nonsense. The strawberry is a plant that bears flowers perfect in both organs." "I am no botanist," said he, "but I know most of yours will 
bear nu fruit." I requested him to point out any that would. He selected two. I inquired, "Can you then see the difference?" "Not now," said he; "I could if they were in blossom." I found him disposed to give no further information. I marked the plants, and when in blossom, could distinguish them at a distance of several feet. There was not one of these to the hundred. Before they were out of blossom, I cast them all out, as I supposed; they spread, and the next season I had a full crop. But finding a few barren plants before they were out of blossom, I dug them all up, and the next season had not a single berry. I then understood the subject, and made it known. In that day we had no hermaphrodite plants.

Yours truly,

\section{N. LONGWORTH.}

\section{CINCINNATI HORTICULTURAL SOCIETY.}

Tне Secretary, at the request of the Society, reported a written statement of how he found the strawberry question in Philadelphia; after some animated discussion, it was moved to accept and file the report, and the finality was ordered to appear in the minutes of the day.

It has long been argued by some distinguished horticultural writers that certain varieties of the straw. 
berry-for instance, Hovey's Seedling-would produce at one time plants with pistillate, and at another time staminate blossoms. This error has been explained by the fact, that a bed of strawberry plants of any known pistillate variety, after standing three or four years, and the fruit falling and decaying on the bed, will produce seedling plants, and of course new varie ties, and these are as likely to be staminate as pistil. late sorts. The following is the

Finality on the Stratiberry. - Wild or cultivated, the strawberry presents, in its varieties, four distinct forms or characters of inflorescence.

1st. Those called Pistillate, from the fact that the stamens are abortive, and rarely to be found without a dissection of the flower. These require extrinsic impregnation.

2 d. Those called Staminate, which are perfectly destitute of even the rudiments of pistils, and are necessarily fruitless.

3d. Those called Hermaphrodite or perfect, having both sets of organs, stamens and pistils, apparently well developed. These are not generally good and certain bearers, as we should expect them to be. With few exceptions they bear poorly, owing to some unob. served defect, probably in the pistils. One-tenth of their flowers generally produce perfect and often very large berries, 
4th. A rare class-a sort of subdivision of the preceding- - has not only hermaphrodite flowers, but also some on the same truss that are of the pistillate character; and sometimes, in the same plant, a truss will be seen on which all the flowers are pistillate.

Now these four divisions are natural and real; they are also founded upon permanent character, so far as we have been able to discover, after a most thorough investigation, extending through a long series of years, during which millions of strawberry blossoms have been examined with the severest scrutiny. Other forms may exist, and it is not claimed to be impossible that we may yet find a seedling which shall have the general character of a pistillate, that may show an occasional perfect or hermaphrodite flower, as a peculiarity of that individual, but we have never yet observed such a variety; and, further, we believe that whatever impress, as to peculiarities of foliage, pubescence, habit, inflorescence, or fruit, each distinct seedling may receive with its origin, it will be retained in its increase by runners, so long as the variety remains extant. Seedlings may vary from the parent, but off-shoots will not be materially different, except by accidental malformation or by development of unim. portant organs.

JoHN A. WARDER, Secretary. 
APPENDIX.

\section{APPENDIX D.}

From the " "ㅍorticulturist," August, 1854. By P. BARrY, Editor.

THE CULTIVATION OF THE STRA WBERRY

The discussion of the Strawberry question, which has occupied the pages of agricultural and horticultural journals so largely for a few years past, has been the means, directly and indirectly, of advancing materially the cultivation of that fruit. We find ample evidence of this in the more abundant supply of our markets, and in the production of a large number of seedling varieties. Recent letters from correspondents in all parts of the country, as well as the reports of late exhibitions, all testify to the very general interest which is felt on the subject, and the progress that has been made. But, after all, we are constrained to say that our cultivation is yet very indifferent. The size and appearance of the great bulk of fruit offered in market, convince us of this. Those who know how to cultivate are in many cases slovenly, or act upon the principle that good culture will not pay; while there are many who fail for want of correct information. We have now before us a large number of inquiries on the subject. One wants to know how to prepare the soii; another, whan to plant; and another, how to $6^{*}$ 
plant. Several correspondents who are well informed on the subject of cultivation, ask us to give them the names of the best perfect-flowering sorts, as they are tired of keeping separate the staminate and pistillate varieties. We have therefore thought it might be well to offer a few hints which will serve as a general answer.

We will state here, at the sutset, that to cultivate the strawberry successfully, ss but a simple matter. To grow large, handsome, fire-flavored fruit in abundance, it is not necessary to employ a chemist to furnish us with a long list of specifics, nor even to employ a gardener by profession, who can boast of long years of experience. Any one who can manage a crop of corn or potatoes, can, if he will, grow strawberries. We say this much by way of encouragement, because so much has been said in regard to various methods of culture, and various applications and specifics, that some people have become persuaded that a vast deal of learning and experience is necessary to produce large crops of strawberries.

Judging from what we have seen, we believe that the great cause of failure is negligence. The strawberry plant-not like a tree, which when once set in its place, remains there-is constantly sending out shoots (runners) in all directions, taking possession of the ground rapidly around the parent plant. In a 
short time, therefore, unless these runners are kept in check, the ground becomes entirely occupied with plants, the parent plants become exhausted, and the ground can no longer be stirred or kept in such a condition as is necessary to sustain their vigor. The result is, the ground is covered with a mass of starved and weakly plants, choking up each other in a hard, uncultivated soil, and producing a spare crop of small, insipid berries, that dry up on their stalks before they are ripe, unless rain happens to fall every day.

The constant stirring of the soil around the plants is one thing which in our climate is absolutely necessary; and any system of culture which precludes this, or throws any obstacle in its way, is defective. If any one will examine bis strawberry beds, he will find the plants along the outer edges of the beds, where the soil has been kept clean and fresh by the frequent use of the hoe, vigorous and healthy, with luxuriant darkgreen foliage, and large, fine fruit; while in the interior of the beds, where the plants have grown into masses, and covered all the ground, so as to prevent its cultivation, they are yellow and sickly-looking, and the fruit poor and wortless. This we see in our own grounds, and everywhere that we find plants growing under similar circumstances. Does this not show the necessity of cultivation close around the plants? No mattor bow deep we may trench the soil, or how unsparing 
we may be with manures, or how copiously we supply moisture, this cultivation cannot be dispensed with, if we aim at producing fine fruits, and abundance of them. "But," says one cultivator, "by allowing the ground to be all occupied with plants, we save all the labor which would be consumed in removing the run. ners, and we avoid the necessity of applying a mulching to keep the fruit clean." Very true, you save some expense; but what do you get in return? A crop of fruit not fit for the table-small, insipid, and so dirty, if a heavy rain occurs about ripening-time, that it must be put through the wash-tub before it is placed on the table. It is possible that the market-grower may be able to produce berries of this kind at a less price per quart than he could by a careful, cleanly, and thorough system of culture; but then he can expect to sell such fruit only when no better can be had. We have some doubts, however, as to the economy of bad culture in the long run. If a proper system were adopted at the outstart, and followed up with regularity, it would not be found so profitless or expensive. In this, as in every other kind of culture, a system is absolutely necessary. A certain routine of operations which are easily executed if taken at the right time, become burdensome when deferred; and being so, they are not unfrequently put off altogether. Precisely thus it is that strawberry beds are neglected, both in marke 
gardens and private gardens, until they are grown wid beyond hope of recovery. Now, we say to every one who wishes to cultivate strawberries, resolve at once upon abandoning the "lazy-bed" system; and if you cultivate but a square rod, do it well.

We advise planting in rows not less than two feet apart, unless ground be very scarce, when eighteen inches might suffice, and the plants to be twelve to eighteen inches apart in the rows. In extensive field culture, the rows should be at least three feet apart, in order to admit the use of the plough and cultivator. between them, or even the passage of a cart to deposit manures or mulching material. The spade and wheelbarrow are too costly impliments for an extensive culture where labor is scarce and high, as with is. From the time the plants are set until the fruit is gathered, the runners should be cut away as fast as they appear, and the ground be kept clear of weeds, and well worked.

In the fall, or before the setting in of winter, a mulching of half-decayed leaves or manure should be placed between the rows, coming close around the plants, leaving the crown or heart uncovered. This mulching prevents the plants from being drawn out and weakened, or destroyed by freezing and thawing in winter. We have sometimes covered the entire beuls, plants and all, with newly-fallen leaves; and by 
raking them off early in the spring; the plants came out in fine order. In the same way we have coverea with clean wheat straw, and found it answer well. In all the Northern and Western States, some winter protection is of great service, although not indispensable. In field culture, the earth might be ploughed up to the plants, as is done with nursery trees, in such a manner as to afford considerable protection against the action of frost on the root.

As soon as the fruit begins to attain its full size, and approach maturity, the spaces between the rows, which up to this time have been under clean culture, should be covered with straw, litter, or moss. This will serve the double purpose of keeping the fruit clean and retaining the moisture in the soil. When copious supplies of water are to be applied, which should always be done when practicable, stable litter is a good mulching, as the water poured on it carries down with it to the roots of the plants the fertilizing materials which it contains.

The application of water in abundance we must again recommend to all who want the finest fruit. Rains are very good, but they cannot be relied upon, and they always deprive the fruit of its flavor, while artificial waterings do not. On this account the French gardeners say that the strawberry "prefers water from the well to water from the clouds." It is 
suprosed that the electricity which pervades the atmosphere during our summer rains affects the flavor of the fruit.

When the crop has been gathered, the mulching material between the rows should be removed and the ground be forked over, so that if plants are wanted to form a new plantation, their growth will be encour. aged. The same plants should not be relied upon for - more than two crops. The labor of making a new bed, save the trenching of the soil, is no more than that of planting a plot of cabbages.

As to the season for planting, we would recommend the spring for large plantations, because then there is comparatively no risk of failure. The amateur, how. ever, who wishes only to plant a bed in his garden, may do it at any time that he can procure good plants. If the growth of runners is encouraged in July, after the fruit is gathered, good, well rooted runners may be had about the first of September, or it may be sooner. The young plants nearest the parent plant should always be chosen, if possible. In planting during the month of August or September, rainy weather should be chosen, if possible, but it may be safely done, even in a dry time, by using water freely. Water the plants well before taking them up, as it injures the roots very much to draw them out of dry ground; then water the soil thoroughly where they are to be set, before plant. 
ing. A sprinkling will be of no use : it must go down deep, as a heavy rain would. Set the plants in the evening, and shade them a few days with boards set on edge, forming a sort of roof over them. Mulch them, too, with short litter; and it will be well, if the plants be large, to remove some of the lower and larger leaves. Planting can be done safely in spring any time until the plants are in blossom-and all summer, for that matter, with proper care.

We have thus briefly sketched the principal opera. tions in strawberry culture; not in regular order, it is true, but we hope so as to be understood. We are not writing a book, and cannot enter into all the details with minuteness. We have said nothing of the soil, and will only remark that any good garden soil fit to produce culinary vegetables, or any good farm land fit for grain or root crops, will produce good strawberries; but it must be deeply ploughed, or trenched, say twenty inches at least, and liberally manured with well-decom posed stable manure or a good compost. The quantity of manure must vary according to the degree of natural fertility of the soil. In one case, a quantity equal to six inches deep all over the surface would not be too much; while in other cases, half that would be enough.

We would prefer not to make a strawberry planta. tion twice on the same ground; but when circumstances render it inconvenient to change, rows of young plants 
might be set, or allowed to establish themselves from the runners, between the old rows, which can then be turned under with the spade, and will serve to enrich the ground.

Now as to varieties. On this point there is room for a great diversity of opinion, and we cannot hope to name a list that will be acceptable to a very large number of persons, at least in many parts of the country. Planters must have recourse to the best experience to be found in their respective localities; in the mean time we shall express our opinion of a few varieties, and let it go for what it is worth.

It happens that in this country the greater number of our most productive varieties have but one set of the organs of fecundation. A fruitful flower must have both pistils and stamens perfectly developed. The stamens are regarded as the male organs, and the pistils the female. When a flower has well-developed pistils, but no stamens, or imperfect ones, it must be impregnated by pollen from other flowers. Where a flower has no pistils, or has imperfect ones, it is utterly barren. A large number of our best American varieties-such as Hovey's Seedling, Burr's New Pine, McAvoy's Superior, Moyamensing, \&c.-are wanting in stamens, and therefore foreign impregnation is neces. sary. In Europe this distinction is not observed to any extent, and all the English and continental varie 
ties, as far as wh know, are hermaphrodite. In this country very many of them fail from an imperfect development of the pistils, and are consequently barren, owing doubtless to the effects of climate and culture. It is not necessary that the two should be in close proximity; they are sure to get impregnated, if in the same garden, as the pollen is carried about from one flower to another by insects. The beds of the different sorts may be kept entirely separate. Mixing them up is a bad way, as the one outgrows and overruns the other, and they become so confused that nothing can be done with them. On this account many have grown tired of keeping up the distinction, and have resolved to cultivate hermaphrodite sorts only.

The following varieties are the best on the long list of those we have tested on our own grounds:

Pistillate.-Burr's New Pine, Jenny's Seedling, McAroy's Superior, Hovey's Seedling, Moyamensing; Monroe Scarlet, and Crimson Cone. The finest flavored variety among these is Burr's New Pine; the largest, Hovey's Seedling; and the finest and best for market, Jenny's Seedling and Crimson Cone. Hovey's Seed. ling, in Western New York, and in many parts of the West, is a very moderate, and, in many cases, a poor bearer. We have had no crop so heavy the past senson (when all bore well) as on the Monroe Scarlet. 
Staminate, or Hermaphrodite.-Large Early Scarlet, Walker's Seedling, Iowa, Boston Pine, and Genesee. All these may be grown successfully for market, and are good, without being first-rate in flavor. We think much more of Walker's Seedling now than we did last season. It is very hardy, and a great bearer. It appears to be a seedling from the Black Prince. The Boston Pine is the most uncertain on the whole list; without good soil and culture it fails entirely.

Besides the above list, we would recommend to amateurs, who are willing to bestow thorough cultiva tion and care on their plants, the British Queen, which, when well grown, surpasses in size, beauty and excel lence, any we have named. The Bicton Pine, a large and beautiful white variety, which ripens late. We have had a fine crop of it this season, although our plants-being set last year-were seriously injured last winter. Like all the foreign sorts, it needs protection, and a deep, rich soil, with abundant moisture. The Wood Strawberries-red and white-bear most profusely in all places and last a long time; besides, they part freely from the calyx, and are therefore easily and rapidly picked, and their flavor is rich and agreeable to most people. In addition to these, we must mention the Bush Alpine, (having no runners), perpetual bear. ers if kept liberally supplied with moisture. Ther 
deserve much more extensive cultivation than they now receive. With their assistance, we may enjoy strawberries not one month only but four months.

\section{APPENDIX E.}

\section{LETTER FROM PETER B. MEAD.}

September 1st, 18504.

R. G. Pardee, Esq.: Dear Sir-Your request, that I would gire you a few remarks on the culture of the strawberry, I will now comply with, but necessarily in a brief manner. First let me say, that I am glad to learn that you are about to publish a manual On Strawberry Culture. Your long experience and marked success will enable you to invest the subject with unusual interest.

We cannot always command just such a soil as we want; but we generally have the material at hand to modify it so as to answer our purpose very well. For the strawberry I prefer a sandy loam, well drained, and a southern exposure. An eastern aspect is alsc good. Animal manures I do not much use, except on a few of the hermaphrodites, and then very sparingly, and only that which is well decomposed. I much prefer prepared muck, leaf-mould, \&c. .When a stimu. 
lant is required, a solution of guano, the salts of am. ınoma, dilute tannic acid, cr a top-dressing of guano,* superphosphate of lime, pc ash, \&c., answers the pur. pose well. I prefer the ammonia and tannic acid. In a garden, strawberries should be planted in beds, and each kind kept distinct. Make the beds three feet wide, put three plants in a row, the two outside ones being six inches from the edge of the bed; the plants will then be one foot apart. The rows should be eighteen inches apart; but in a small garden they may be one foot apart. Select young plants in preference to old ones. Set the plant up to the crown, but do not cover it. Keep the ground open and porous, and free from weeds. A word as to to the best time for planting. I prefer early spring; but where a supply of water is at hand, it may be done at any time; for only give the strawberry plenty of water, and it will defy any amount of heat. I would remark, en passant, that whoever attempts to water his strawberries must do it thoroughly, if he would have his plants derive any benefit from it. A thorough soaking once a week will do more good than fifty sprinklings a day. Where water is not at hand, the planting should be done during Aug tst and

* Further experience has led me to discard the use of guano, particularly as a top-dressing. It is not only too stimulating for the strawberry, but rapidly dissolves the vegetable constituents of the soil, which I cousider essential to the plant.-January, 1856. 
September, taking advantage of a heavy rain. I prefer the early part of September; in fact, I have planted Hovey, Burr's New Pine Walker's Seedling, and others, as late as the 21st of October, and every plant survived the winter without covering of any kind; but I would not recommend nlanting later than September.

Next, a few words about mulcker w and after-treatment. Latterly I have seldom resorteả tr. mulching. I have a rake seven inches wide with prongs eight inches long, made of highly tempered steel. This is my mulcher. With this instrument I work between the rows from spring till fall; and frequently when the plants are in fruit. I know I shall be told that this is a dangerous practice, and I admit that it is in inexperienced hands; indeed, I would not trust another to use it among my own plants, owing to the danger of injuring their fibres; and yet I use it myself within an inch of the crown. When, therefore, I cannot give the necessary personal attention to my plants, I resort to the next best mulcher, which is tan, either spent or fresh. I prefer the latter. The ground should first be well stirred, and the tan applied not more than one inch - thrck. If too much is applied it is apt to ferment and kill the plants. Many fine beds have been destroyed in this way. Where tan cannot be had, leaves from the woods may be used. These make an ad, irrable 
mulch, and promise, in my opiniou, to take the first place among mulchers. Hay, straw, grass, sawdust, \&c., are also good; but whatever is used for this purpose, the crown of the plant: must in no case be covered.

The beds having been properly made, the aftertreatment becomes a very simple matter; indeed, I know of no plant that gives such generous returns at so small a cost of labor; but you must not infer from this that I justify anything like neglect. The beds must be looked over occasionally, runners remuved, weeds pulled up, and everything kept neat and clean. In the spring, rake the mulching into the walks, stir up the soil, apply a top-dressing if needed, and then put back the mulching. The best mode, however, is to apply one of the solutions before mentioned, after the fruit has set. The bearing-season may be considerably prolonged by thorough watering, and will amply repay the trouble where the means are at hand. As soon as the plants have done bearing, they will throw out runners, which must be pinched off, unless plants are wanted for new beds. I have no time to add more here, except to say, that he who would have good. strawberries must cultivate them; by which I mean the npposite of letting them take care of themselves.

You will doubtless expect me to add a few words in regard to some of the leading varieties; but it would? 
be impolitic for me to say much on this point, since you know I am now testing all the new varieties, and conducting a series of experiments having reference to the natural history of this most interesting plant. Friends have furnished me with varieties entirely new, and not yet sent out; but these I have only had under trial since last May, and it would be quite premature to say much about them, though some of them are very promising. I am daily expecting more. At some future time I shall review them all. I do not hesitate to say, however, that the following are good, with. out at present designating them in any other way: McAvoy's Superior, Hovey's Seedling, Moyamensing, Burr's New Pine, Black Prince, Pennsylvania,* McAvoy's Extra Red, (rather acid), Boston Pine, Alice Maude, Longworth's Prolific, Excellente, Walker's Seedling, Beach's Queen, Large Early Scarlet, Angelique. But I rather think I will stop, for I know not where this may lead me. Barr's New White and Bicton Pine are both large white varieties; the former is best.

* Pennsylvania will not bear well or produce good fruit except under generous treatment; certainly not under trees, where, strangely enough, I have seen it while undergoing a trial; and, as may naturally be supposed, a severe trial it proved. To the above list might be added, Scott's Seedling, Kate, Monroe Scarlet, Wilson's Seedling, Barry's No. 1, and others. No. 1, in my opinion, is much the best of Mr. Barry's Seedlings.-January, 1856. 
You also tell me you mean to add some directions about the culture of currants, gooseberries, and other small fruits, as well as the grape. These things should be better grown than they generally are. Gooseberries and currants are usually seen as a mass of half-decayed branches, without form or sightliness. It is next to impossible to bring these into shape, or develop their maximum productiveness. It is better to begin anew. Procure plants struck from cuttings; grow them with a clean stalk not less than six inches in height; prune them every winter, keeping the heads well open, and shorten in last season's growth in the currant, but not in the gooseberry. These fruits are generally planted against the fence, or in some out-of-the-way corner, just where they should not be. Give them an open exposure, plenty of manure, and good culture, and you will be amply rewarded. The Red Dutch is best for general purposes; but Knight's Sweet Red, Cherry, Prince Albsrt, White Grape, and others, may be added whore there is room.

The raspberry and blackberry are also desirable in a garden, furnishing a delicious fruit at an opportune saason. They both require a deep, rich soil. The blackberry may be planted against an east fence, and the raspberry against a west fence-about the best flaces in the garden. The old wood of the raspberry should be cut out after it has ceased bearing, and some 
four or five canes of the new growth retained for next season. The blackberry should be winter pruned, ard shortened in about the last of July. They should botb be tied to stakes or to the fence, and the ground kept free from weeds. Of raspberries, the Fastolf, Red Antwerp, and Yellow Antwerp are among the best. Dr. Brincklè has raised several seedlings, one of which, Col. Wilder, I have grown and found to be good. The above in some localities, will need protection in winter, which is best done by bending down the canes and covering them with earth. Mr. Van Dewenter, of Astoria, has a new everbearing raspberry, which will prove to be an aequisition.*

Of blackberries, the Improved High Bush (of Boston) and the New Rochelle are now pretty well known. The latter is certainly the best, and most productive: it is a most beautiful fruit, and worthy of general cul. tivation. I saw a basket of this fruit from Mr. Rosevelt, of Pelham, Westchester Co., the berries of which measured from three to three inches and a half in circumference. Mr. Lawton has also shown fine specimens. About a year since, while at Chester, Morris

* This is really a continual bearer, heing loaded with fruit until further growth is checked by the severity of the frost. It is a go od fruit of fair size, and ought to be wide'y dissemin ited. The Catawissa, which is represented to possess the same everbearing quali. ties, I have not seen Dr. Brincklè's Orange provis to be among the best of all rasphorries.-Jauuary, 1856 . 
Co., N. J., I saw a blackberry growing wild, closely resembling the New Rochelle, and quite equal to it. I have a variety, however, which I consider superior to eitber of the above in point of flavor. It is very distinct in wood and foliage, and a strong grower. It is a hybrid variety, and may be had of Mr. More, of Yorkville.

To say anything important of the grape in a few lines is no easy matter. The best soil, I apprehend, is a gravelly loam, thoroughly underdrained, and subsoiled or trenched. We expect the vine to yield its fruit for a lifetime at least, and should prepare the soil accordingly. The ground having been trenched, dig a hole not less than three feet square and two feet deep, and fill up nearly a foot with a compost of manure, bones, broken charcoal, lime rubbish, and vegetable mould, or as many of these materials as can be procured, but no dead dogs, cats, or horses. Over this compost put a layer of the best soil; then take your vine, spread the roots in their natural position, and fill up carefully. Vines three and four years old are the best, if they have been properly cared for, otherwise I would prefer those two years old. Pruning is a matter of the first importance. In gardens, vines are grown upon either arbors or trellises, and the same kind of pruning will not answer for both. The arbor is generally used for the purpose of shade as well as fruit, 
and here spur-pruning is generally practised, but carried to such an extreme, that in the course of years the vines become knotty, stunted, and unproductive. The first year, little or no pruning is necessary; if there is much top, however, it must be cut into two or three good-eyes. The vine is very tractable, and may be trained in the most symmetrical manner; this, huwever, is too often done at the expense of the best fruit-wood. In the case of the arbor, after the leaders have been trained to their places, and the vines have come into bearing; do not prune closer than three eyes. If the growth is likely to be too much, rub out the middle eye, leaving the third for fruit, and the first for bearing next year; at which time cut away all the wood down to this first shoot, which latter must be cut to three eyes, rubbing out the second as before, and so on from year to year. The truth is, it would require several pages to explain this matter fully, but I have no time for it. In the case of the trellis, what gardeners call cane-pruning is the best. Select as many shoots as are wanted, and cut out all the rest; these shoots are then shortened into the first good eye; but if this should leave them too long, they must be cut to the desired length. I regret that I have not time to explain this fully; but the principle is, to get rid of last year's bearing-wood, and keep the new wood as near to the body as possible. The grape border must be manured, 
spaded, and cultivated with as much care as you would bestow on a crop of corn. A summer pruning is also necessary, which consists in thinning out the superfluous growth, and pinching in the laterals. The leaves of the grape-vine must in no case be removed. The best time to prune is in the fall and early winter.

The best grapes for this latitude are the Isabella, Catawba, and Early Black, or Madeira; the latter only for the garden; the Charter Oak, Royal Muscadine, (a synonyme), and others of that class, are worthless hum. bugs. The Diana is a small, sweet and rather pleasant grape, and desirable for localities where the Isabella will not ripen.* The Clinton and some others which are well spoken of I have had no opportunity of testing, and I have seen the fruit of many seedlings, which deserve no further mention, with the exception of a white variety with the Catawba flavor, and ripening first of September. I think this last will prove to be a very good grape.

But this letter has reached a great length, and I must close it, with all its shortcomings. If it con-

* I have elsewhere stated, in a report, as the result of further experience, that I consider the Diana valuable for general cultivation; and since then, the American Pomological Society has put it on its general list. It is certainly a fine grape. The Concord, in regard to which there has been so much controrersy, is deserving of a full and fair trial.-January, 1850. 
tains anything of use to you for the purposes of your manual, you are at liberty to do what you please with it.

Sincerely yours, $\quad$ Peter B. Mead.

\section{APPENDIX F.}

THE FRUIT AND VEGETABLE GARDEN.

BY ÁN AMATEUR.

THERE are a few accessories of the homestead more important than a good fruit and vegetable garden; no home is perfect without them. If there is one thing more than another which adds to the comforts of a poor man's cottage, it is a well-kept garden, in its largest sense; nay, it is a luxury, even to the millionaire. A well-regulated house within, and a well-kept garden without, make up much of the sum of human happiness. How few such there are! The garden is too generally looked upon as something to minister to the mere appetite; but, when rightly regarded, it exercises a moral and intellectual influence, which gives it a jstrong claim to the serious consideration of all who feel any concern in the ultimate destiny of the human race. Horticultural pursuits, above all others, bring into healthy play those powers of body and mind, the mutual exercise of which alone can keep up that just 
equilibrium of the physical, intellectual, and moral forces which makes the true man.

I will now submit a few practical remarks on what may be called the Cottage Vegetable Garden, or rather Fruit and Vegetable Garden; for, on a limited plot, they ought not to be separated. There is no good reason why a man with three or four city lots, each 25 by 100 feet, should not indulge the luxury of a few choice fruits, equaliy with him who owns his acres.

In what follows, it is supposed that the lots run n'rth and south, the house being built on the north front, and the flower-garden separated from the rege. table by a rose-trellis the full width of the lots. The flower-garden and lawn will occupy another article.

Let us suppose a man has four lots of ground, two of which are taken up with a house, lawn, flower-garden, \&c. He will then have a plot 50 by 100 for a fruit and regetable garden. Now it will not do to use half of this up with walks-a thing quite too common.

Beginning at the rose-trellis, lay off a central walk four feet wide, through the length of the garden; then, immediately behind the rose-trellis, lay off a grapeborder ten feet wide, and parallel with this a walk three feet wide, stopping three feet short of each sidefence; then borders three feet wide next the east and west fence; then, parallel with these, a walk three feet wide; then a central walk four feet wide, through the 
width of the garden, and a walk three feet wide close to the south fence. This arrangement will make four large central beds, each 40 by 17 feet, besides the borders. The beds and borders should be edged with box, kept closely cut. The whole garden should be trenched two or three feet deep. To make the walks, dig out the soil three feet deep; fill in with stones about one foot, and cover them with stout brush; then put in the soil, and finish with about six inches of coarse sand or gravel, raising the walks a little in the middle. Roll them from time to time till they become settled; a good coating of salt will help to make them hard, and keep them free from weeds. Walks thus made will keep your feet dry, and your beds tolerably well drained-the latter an object which should never be lost sight of, especially where early fruit and vegetables are desired. There are some matters connected with grading and levelling, which must be determined by the circumstances of each particular case. Lastly, there should be some eighteen inches of good soil, of which sod mould is the very best. No amateur can hope to have a good garden, pleasantly worked, unless everything is properly prepared from the beginning, hence these particulars.

Now let us see what permanent "fixtures" are wanted. Four feet from the rose-trellis, put in a row of posts, six or seven feet high and eight feet apart, 
upon which stretch four stout wires. Plant a grape. vine between each post, and keep them well pruned, on the cane system. Eschew all charlatans and hum bugs, whether in the shape of men or vines, and among the latter, especially the Charter Oak. The walk, if made as directed, will keep this border well draineda matter of much moment, where well-flavored grapes are desired. Two or three loads of grarel, incorporated with the soil, would make it still more congenial to the grape. Between each vine, and some three feet from the box edging, put in a rhubarb plant, and under it a good heap of manure. This is a good arrangement, notwithstanding some may object to it. In the centre of this border, where the wide walk intersects it, a summer-house may be erected.

In the border around the east fence, plant the blackberry, some three or four feet apart; in the west border, plant the raspberry at about the same distance. It would be well, however, to reserve a portion of the west border for a few plants of sage, parsley, thyme, \&c.

There now remain the four large beds, the borders of which may be occupied with dwarf fruit trees; no others should ever be grown in a garden; and by no means plant them in an auger-hole. I would recom. mend chiefly pears; but, for the sake of variety, a couple of plums, apricots, cherries, quinces, \&c., may be added. These should be planted in the border of 
the large beds, about three feet from the box edging, and some eight feet apart. Between each tree a currant or gooseberry bush may be planted; these should be raised from cuttings, grown to a single stalk, and regularly winter-pruned. This mode of planting is good in itself, and leaves all but the border of the large beds for the vegetables, strawberries, \&c. One bed may be occupied with strawberries and asparagus, but the latter must be kept three or four feet from the fruit trees.

Having disposed of the principal permanent arrangements, let us look for a moment at such vegetables as will have to be raised annually. For this purpose we have left three of the large beds. It is taken for granted that a good supply of well-prepared barn-yard manure has been procured, as well as a set of steel garden implements, which latter should always be kept as bright as a new penny. First make up your mind what you will grow, and how much of it. Then spread on a good coating of manure, and spade twelve inches deep. It is surprising to a novice how much can be grown on a given surface. Beets, carrots, salsify, parsnips, lima beans, and some others, will occupy the ground the whole season. Beets should be sown thick, in drills six inches apart, each alternate row to be used for greens, as well as the thinnings of the others. Between the carrots, \&c., radishes may be suwn. 
Leutuce, radishes, \&c., may be sown in the raspberry and blackberry borders. Peas should be sown iu double drills six inches apart, at intervals of three feet. Between the peas may be planted beets for greens, radishes, spinach, lettuce, \&cc., making two drills of each. The peas will come off in time for turnips, late cabbage, brocoli or celery; the latter should be planted in beds, the earth thrown out one spade deep, the celery planted in rows, one foot apart, and the plants from six to ten inches in the rows. Snap beans will be off in time for cabbage, turnips, fall spinach, \&c. If beans are wanted in the fall, they may follow onions, where these have been grown from sets. A few cucumbers may be planted in the fruit border. Sugar-corn should be planted in drills three feet apart, the plants six inches in the drills for the small early varieties, and about a foot for others. For a succession, plant from early spring till the first week in July, two or more drills at a time, according to the wants of the family. Corn map may be planted after some of the crops named above. If one piece of ground is used, a portion of it will give you some early spinach and peas. Radishes may also be planted from time to time along the fruit border, but too much of that will injure the trees. A few egg-plants and peppers may also be planted in the fruit border, but not immediately under the trees. By the exercise of a little 
jųdgment, a variety of things may be made to follow each other in this way, so that no spot of ground need necessarily remain unoccupied for a single day during the whole season.

The ground must be kept free from weeds, and well worked at all times. When the weather is dry, use the hoe more frequently than usual, (a narrow, low-pronged rake is best), which will enable the ground to absorb moisture from the atmosphere, of which it always contains some, even in the dryest weather. Frequent stirring of the soil is important in another respect, in keeping it open and porous, and enabling it to take up the gases of the atmosphere, which constitute no inconsiderable portion of the food of plants. It will also give an earlier and better crop. Discard the practice of earthing your plants, except for the purpose of blanching. Hilling should not be tolerated, except in soils naturally retentive of moisture; the true remedy for which consists in underdraining, and not in hilling. The preceding remarks are mostly of a general nature, but a few words may be said here of the time and labor necessary to cultivate and keep in order a garden like that here described. A person familiar with the operations to be performed, and expert in the use of implements, can generally perform the necessary labor (unless he is dronish) without detriment to his daily business; on the contrary, he will find himself 
invigorated for the discharge of its duties. At.all events, he will need but a few days' assistance for the rough work. I know that very much more than this has been done for years and will continue to be done. I speak this for the encouragement of those who desire to surround their homes with these luxuries, but whose means will not permit them to employ a permanent gardener. Much time is lost for want of proper knowledge. The best advice I can give the novice is, first to learn what is to be done, and then learn how to do it, and always do it well. May the day come when even the common laborer shall be blessed with the comforts of a good home, and rejoice "under his own vine and" fruit "tree!" 



\section{B A R R Y'S}

\section{FRUIT GARDEN.}

\section{By P. BARY.}

\section{NOTICES BY THE PRESS.}

"Barry's Fruit Garden" is one of those practical, profusely illustrated, and comprehensive manuals which Orange Judd \& Co. delight to publish. It seems to tell almost every thing which one book can tell about the ins and outs and ways and means of fruit culture.-The Advance, (Chicago.)

This volume of 490 pages, as its title implies, is deroted to the culture of fruits of every variety in orchards and gardens. It describes the cliseases incident to the various fruit trees, the kinds of insects that prey upon them, and the remedies for ridding trees of the evil. - Scientific American.

The author writes from his own practical experience; and that experience is of no ordinary character, being the result of more than thirty year's' work at the liead of the largest w ursery in America, where every operation is conducted with eminent skill.-The Country Geritleman.

It explains all the minutix of fruit-gardening, even to the implements, copiously illustrated by engravings, so that the merest novice need not err; gives descriptions of all the different kinds of fruit that can be raised in our climate in every stage of their lives, from the germ to the fruit-bearing period, with instructions in pruning and grafting, in a most satisfactory manner. The chapter on grapes alone is worth more than the price of the book.-Jersey City Times.

It is a rich mine of information upon fruits of all kinds and their proper culture.-Providence Press.

Mr. Barry has long been known as an authority upon fruit culture, and this volume of 490 pages, with a full and carefully prepared inclex gives the latest results of his study and experience.-sipringfield Republican.

This beautiful volume, of nearly five hundred pages, will be cordially welcomed by every lover of nature. It is the most perfect work we have seen on the whole subjoct, and well cleserves awide circulation.- - Tnited Presbyterian, (Pittsburgh.)

We have orchardists, strawberry books, grape books, small fruit books, and all that; what we want is one book for them all. Here we have it. It is quite a scientific work, too, giving more than mere arbitrary directions; we have the grounds for them. May we rely on what it says? A sufticient answer is that it comes from the office of the American Agriculturist.-Zion's Herald.

FROM HON. MARSHALL P. WILDER.

PRESIDENT OF THE ANERICAN POMOLOGICAL SOCIETT.

Boston, April, $18 \%$.

GENTLEMEN: I have perused with great pleasure the new and improved edition of Mr. Barry's book. It is in every respect desirable, and will receive the approbation of our best pomologists. It is the result of a long life of experience, and admirably calculated to meet the demands of our age. I give it a hearty welcome. Marshall P. Wilder.

Price, Post-paid, \$2.ธо.

\section{ORANGE JUDD \& COMPANY,}

\section{Broadwry, New-Iork.}




\title{
PEACH CULTURE.
}

BI

\section{JAMES ALEXANDER FULTON,}

DOVER, DELAWARE.

\section{ILLUSTRATED.}

WrтHIs the last few years, fruit culture, in all its varieties, has greatly in. creased in this country; so that, to-day, it is one of the leading interests. Among the fruits, the PEAcH, if not the most, is one of the most important of all. It is so easily raised, comes into bearing so soon, and is so delicious, as well as beautiful, it is impossible that it should not be a favorite. The consequence is that, in the sections specially conducive to its cultivation, almost every farm has an orchard, and some farms are but one continuous orchard; and sometimes farm after farm is devoted to Peaches. Some planters have set as many as twenty thousand trees in a single season. Orchards of twenty, thirty, and fifty acres are not at all infrequent. Living in the very centre of the peach-growing district; sharing the common interest felt in the subject; deeply impressed with its importance to the individual planters themselves, and also to the community at large; and believing that a lasting benefit could be done to both, the author has been induced to prepare, and now offers to the public, this work on Peach Culture.

\section{CONTENTS.}

INTRODUCTION.

CHAPTER I.-Site of Nursery.

Chapter II.-Seed.

Chapter III.-Seed-bed.

Chapter IV.-Preparation of Ground for Nursery.

Chapter V.-Planting the Seed.

Chapter VI.-Nursery Cultivation.

Chapter VII.-Buds.

Chapter VIII.-Budding.

Chapter IX.-Cultivation of Buds.

Chapter X.-Taking Up and Sending to Market.

Chapter XI.-Selecting a Site for an Orchard.

Chapter XII.-Planting an Orchard.

Chapter XIII.-Orchard Cultivation.

Chapter XIV.-Coming In.
Chapter XV.-Baskets and Crates. Chapter XVI.-Transportation. Chapter XVII.-Consignees. Chapter XVIII.-Ladders. Chapter XIX.-Shipping. Chapter XX.-Picking. CHAPTER XXI.-Returns. CHAPTER XXII.-Markets. Chapter XXIII.-Profit. Chapter XXIV.-Cultureafter a Crop Chapter XXV.-Uses. [eases. Chapter XXVI.-Insects and DisChapter XXVII.-Special Culture. Chapter XXVIII.-ThePeach-House Chapter XXIX.-Varieties. [logue. Chapter XXX.-Descriptive CataChapter XXXI.-Fancy Varieties.

\section{Price, Post-paid, . . . . . \$1.50.}

\section{ORANGE JUDD \& COMPANY,}

\author{
245 Broadway, New-Iork.
}




\section{GRANBERRY GULTURE. BY JOSEPH J. WHITE,}

A. Practical Grower.

IIIUTSTR AIEI.

NOTICES BY THE PRESS.

The book is profusely illustrated, contains minute directions for preparing the ground, setting and cultivating the plants, flowing the plantations, and picking and marketing the fruit.-Springfield Republican.

As the business of cranberry culture is largely and rapidly increasing, sucb a book as this will prove to many an efficient and profitable guide.-Detroit Advertiser and Tribune.

This is decidedly the best work out on the cranberry.-Practical Farmer, (Phila.)

It is a practical compact treatise, full of all necessary details, fully illustrated, and must satisfy all wishing a complete and thorough guide to cranberry growing.-Maine Farmer.

The man who is growing cranberries, if he have enterprise, and a good conscience, and eats his own cranberries, or expects other people to eat them, ought to get this little book. - Chicago Tribune.

We judge this to be the best book on cranberry culture yet published.-Prairie Farmer.

The work is very comprehensive in its details, and wilı be invaluable to those who have an interest in the subject.-Pittsburgh Dispatch.

A thoroughly practical manual, and one apparently prepared to answer any and every question which any one may be moved to ask on the subject discussed.-Congregationalist and Recorder.

It seems to be a complete manual on a branch of horticulture which is of growing importance.-Lowell Daily Courier.

We consider it invaluable to the fruit grower.-The Courier, (N. J.)

The directions in regard to forming beds cr plantations are so plain that any person could follow them. The various illustrations and diagrams aid much in conveying correct ideas in regard to the different subjects.-The State Republican, (Mich.)

\section{PRICE, POST-PAID, \$1.25. ORANGE JUDD \& COMPANY,}

245 Broadway, New-York. 


\title{
PARSONS ON THE ROSE.
}

A TREATISE ON THE

\section{Propagation, Culfure, and History of the Rose.}

\author{
By SAMUEL B. PARSONS.
}

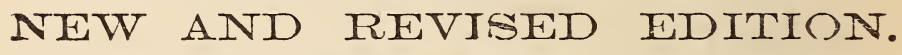

\section{ILLUSTRATED.}

Tue Rese is the only flower that can be said to have a history. It is popalar now, and was so centuries ago. In his work upon the Rose, Mr. Parsons has gathered up the curious legends ccncerning the flower, and gives us an idea of the esteem in which it was hcld in former times. A simple garden classification has been adopted, and the leading varieties under each class enumerated and briefly described. The chapters on multiplication, cultivstion, and training, are very full, and the work is altogetner the most complete of any before the public.

The folwing is from the author's Preface:

"In offering a new edition of this work, ths preparation of which gave us pleasure more than twenty years ago, we have not only carefully revised the garden classification, but have stricken out much of the poetry, which. to the cultivator, may have seemed irrelevant, if not worthless. For the interest of the classical scholar, we have retained much of the early history of the Rose, and its connection with the manrers and customs of the two great nations of a former age.

"The amateur will, we think, find the labor of selection much diminished by the increased simplicity of the mode we have adopted, while the commercial gardener will in nowise be injured by the change.

"In directions for culture, we give the results of our own experience, and have not hesitated to avail ourselves of any satisfactory results in the experi ence of others, which might enhance the utility of the work."

\section{CONTENTS:}

Chapter I.-Botanical Classification.

Chapter II.-Garden Classification.

ChAPTER III.-General Culture of the Rose.

ChAPTER IV.-Soil, Situation, and Planting.

CHAPTER V.-Pruning, Training, and Bedding.

Chapter Vi.-Potting and Forcing.

CHAPTER VII.-Propagation.

CHAPTER VIII.-Multiplication by Seed and Hybridizing.

CHAPTER IX.-Diseases and Insects Attacking the Rose.

CHAPTER X.-Early History of the Rose. and Fables Respecting its Origin. Chapter XI.-Luxurious Use of the Rose.

Chapter XII.-The Rose in Ceremonies and Festivals, and in the Adorn: ment of Burial-places.

Chapter XIII.-The Rose in the Middle Ages.

Chapter XIV.-Perfumes of the Rose.

Chapter XV.-Medical Properties of the Rose.

Crapter Xi,-General Remarks.

PRICY, POST-PAID $\$ 1.50$.

ORANGE JUDD \& CO.,

245 Broaduay, New-Iork. 


\title{
PRACTICAL FLORICULTURE,
}

A GUIDE TO THE

GUCCESSFLL PROPAGATION ANI) CULTIVATION OF

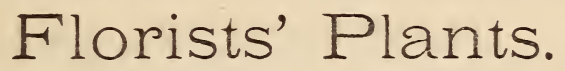

BY PETER HENDERSUA, BERGEN CITY, N. J.

Mr. Henderfon is known as the largest Commercial Floriat in the country In the present work he gives a full account of his modes of propagation and cultivation. It is adapted to the wans of the amateur as well as the professional grower.

The scope of the work may be judged from the following

\section{TABLE OF CONTENTS.}

Aspect and Soil.
Laying out Lawn and Flower Garden.
Designs for Flower Gardens.
Planting of Flower Beds.
Soils for Potting.
Temperature and Moisture.
The Potting of Plants.
Cold Frames-Winter Protection.
Construction of Hot-Beds.
Greennouse Structures.
Modes of Heating.
Propagation by Seeds.
Propagation by Cuttings.
Propagation of Lilies.
Culture of the Rose.
Culture of the Verbena.
Culture of the Tuberose.

\author{
Orchid Culture. \\ Holland Bulbs. \\ Cape Bulbs. \\ Winter-Flowering Plants \\ Construction of Bouquets. \\ Hanging Baskets. \\ Window Gardening. \\ Rock-Work. \\ Insects. \\ Nature's Law of Colors. \\ Packing Plants. \\ Plants by Mail. \\ Profits of Floriculture. \\ Soft-Wooded Plants. \\ Greenhouse Plants. \\ Annuals. \\ Hardy Herbaceous Plantes
}

Diary of Operations for each Day of the Year.

\section{ILLUSTRATED.}

BEIT POST-PAID. PRIUE, \$1.30

\section{ORANGE JUDD \& COMPANY,}

\section{BROADWAY, New-Yorh}




\section{GARDINING FOR PROFIT:}

A GUIDE TO THE SUCCESSFUL CULTIVATION OF THE

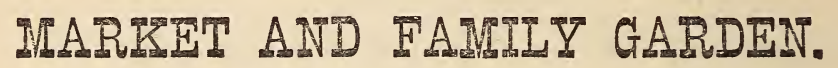

By Peter Henderson.

\section{FINPIJ ILIUSTRATED.}

This work has had a constant and remarkable sale ever since it was issued, and the later enlarged and revised edition is as well received as was the first. It was the first work on Market Gardening ever published in this country. Its author is well known as a market gardener of many years' successful experience. In this work he has recorded this experience, and given without reservation, the methods necessary to the profitable culture of the

\section{MA ARIXIT GATEDN.}

It is a work for which there was an urgent demand before its issue, and one which commends itself, not only to those who grow vegetables for sale, but to the cultivator of the

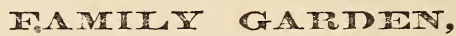

to whom it presents methods quite different from the old ones generally practiced. It is an omigiNAL AND PURELY AMERICAN work, and not made up as books on gardening too often are, by quotations from foreign anthors.

Every thing is made perfectly plain, and the subject treated in all its details, nm the selection of the soil to preparing the products for market.

\section{CONTENTS.}

Men fitted for the Business of Gardening.

The Amount of Capital Required, and

Working Force per Acre.

Profits of Market Gardening.

Iocation, Situation, and Iaying Out.

Soils, Drainage, and Preparation.

Manures, Implements.

Uses and Nianagement of Cold Frames.

Formation and Management of Hot-beds.

Frorcing Pits or Greenhouses.

Seeds and Seed Raising.

How, When, and Where to Sow Seeds.

Transplanting Insects.

Packing of Vegetables for Shipping.

Preservation of Vegetables in Winter.

Vegetables, their Varieties and Cultivation.

In the last chapter, the most valuable kinds are described, and hie culture proper to each is given in detail.

\section{Sent post-paid, price $\$ 1.50$.}




\title{
Gardening for Pleasure.
}

\author{
A GUIDE TO THE AMATEUR IN THE
}

\section{FRUIT, VEGTABLI, AND FLOWIR GARDEN,}

WITH FULL DIPECTIONS FOR THE

\section{GREENEOUSE, CONSERVATORY, AND WINDOW-GARDEN.}

\author{
By Peter Hexderson.
}

ACTHOR OF "GARDEXING FOR PROFIT," AND "PRACTICAL FLORICLLTURE."

\section{Illustrated.}

\section{EDITORIAL NOTICES.}

ONE of the most popular works of recent rears on similar topics was the "Gardening for Profit" of Mr. Peter Hexdensos, the Well-known florist of Jersey City. He has been equally fortunate in the title of a new book from his pen. just published by tile ORArige JUDD Co.. of New-York - "Gardening for Pleasure." The author has a happy faculty of writing for the most part just what people want to know $\rightarrow 0$ that, although his books are neither exhaustive nor especially elaborate, they proceed to the gist of the subject in hand with $s 0$ much directnes: and simplicity that they fill a most important and useful sphere in our rural literature.-The cultivator und Couritry Gentiemen, dioceny, .T. Y.

IT gives, in a clear, intelligible form, just the information that novices and even experienced cultivators wish to have always accessible, and will be specially raluable to those who keep house plants.-The Ubsercer, NewYork lity.

Mr. Peter Hexdersoy has followed up "Gardening for Profit" with "Gardening for Plea-ure," into which is packed much useful information about window-gardens, the management of flower-beds, etc.-The Irueperident, New-lork city.

$\mathrm{HE}$ is a thoroughly practical man, uses plain, common language, and not technical terms. in his statements and explanetions, and puts the staif of knowledge directly into the hands of the amateur and sets him at work. - The Pitess, Pigicilence, R. I.

PEOPle who have money to spend in arlorning their grounds. are told here how to do it to the best adrantage, and ladies are fully instructed in all the art and mrstery of window-gardening. It will prove a meful guicie to all who have a taste for flowers, and also contains practical instructions for the cultivation of fruits and regetables. - The Traricritht. Porthum, .Me.

THIs volume is eminently clear in its style and practical in its directions. Its appearance is timely, as it contains some valuable hints upon winter flowering plants and their proper cultivation, together with plain directions how to raise them from seed and to multiply them by cuttings.Courier-Journal, Louistille, K'y.

Price, post-paid, $\$ 1.50$.

\section{ORAYGE JUDD COUPAYY,}




\section{FARM-GARDENING}

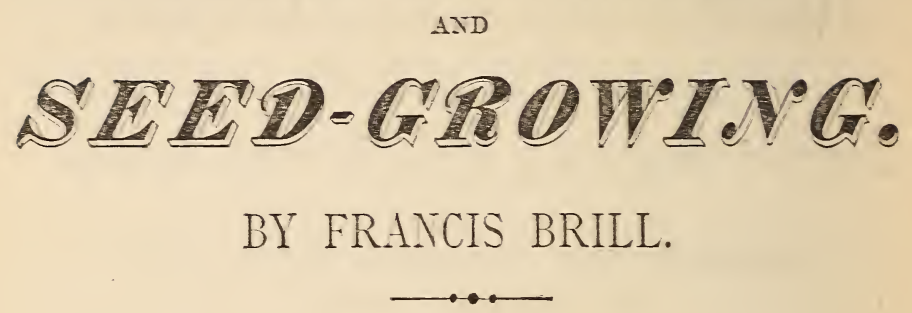

NOTICES BI THE PRESS.

Orange Judd \& Co. have added to their splendid catalogue of agricultural books "Farm-Gardening and Seed-Growing," by Francis Brill: it is practical. plain. compl te, and satisfactory, so that for a small amonnt of money a great deal of desirable information can be obtained. If there is any firm antwhere which is to-day di-seminating so much knowledze in recard to tilling of the soil, as this same said rirm of Orange Judd of Co., we wiil present a medal to our informer.- Watcliman and Reflector: (Buston.)

The want occasionally expressed to $u s$ of a work on the cognate subjects above named, (Farm-Garlening and Seed-Growing, is now met in a book under this title, from the pen of Mr. Franci= Brill, formerly a market-gardener and seed-grower at Newark. $T$. J.. and at preseut engaged in raising seeds at Matiituck, L. I. Its directions are concise and practical, covering those points on which a beginner is most likely to require information.-Country Gentleman.

It seems to be a rery sensihle. practicni work hy a practical man. $\mathrm{Mr}$. Brill's father wis a gardener: and ..e himself has har an extensive experience, and he talks ahont what he knows. which is more than can be said of meny authors of industrial work:-IFoore' \& Rural Herc-Iorker.

There can be no question that this farm-gardening can be made in many dis. tricts of the Sonthern Atlantic States, especially near the coast, far more profit. able than growing the ordinary staple crops. "In connection with producing the vigetables, the growing and saving their seeds receive minute attention.American Famer, (Baltimore.)

This indnstry is now occupring the attention of mans persons who sell their products to the great seed-houses, and novices twho have the facilities, and wish to enter upon the business, will find in this book just the hints needed.-Sprinafield Republican.

Mr. Brill has been a successful farm--sardener and seed-ørotrer for a number of ye rs. and gives in a clear and concise form the knowledge he has gained. ....It gives the best method of manuring. planting. and cultrating every vegetable sold in market-in short, erery thing required is be known, plainly and fuily-and should be in the hands of every one who cnlivates so much as a rod of land for family use, pleasure, or pront.-Sufari (L. I.) Times.

The seal of Orange Judd \& Co. upon an agricultural publication is suficient guarantee of its worth. Francis Brill's book, published by them. is a very complete work. giving plain. minute instrnctions as to raising, toking care of. and bringing it market, those vegetables which are most in demand in the large cities, and those seeds which are being called for throughout the country. -1. Y. Eiening Irail.

$$
\text { Price, Post-paid, \$1.00. }
$$

\section{ORANGE TUDD E COMPANT,}

\section{BROADWAI, NEW-IORK.}




\section{AMERICAN CATILE: \\ Their History, Breeding, and Management.

\author{
By IEWIS F. ALLEN,
}

Lato President New-York State Agricultural Society, Editor "American Short-Lorn Herd Book," Author "Rural Architecture," etc., etc.

\section{Notices by the Press.}

WE consider this the most valuable work that has recently been issued from the American press. It embraces all branches of the important subject, and fills a vacancy in our agricultural literature for which work the author, by his inany years' experience and observation, was eminently fitted. . . I It ought to be in the hands of every owner of cattle, and the country, as well as individuals, would soon be much richer for its teachings.-Journal of Agri. culture, (St. Louis.)

The large experience of the author in improving the character of Ameri. can herds adds to the weight of his observations, and has enabled him to produce a work which will at once make good its claims as a standard authority on the subject. An excellent feature of this volume is its orderly, methodical rrangement, condensing a great variety of information into a comparatively mall compass, and enabling the reader to find the point on which he is seeking light, without wasting his time in turning over tise leaves. $-N$. $Y$. Tribune.

This will rank among the standard works of the country, and will be considered indispensable by every breeder of live-stock.-Prictical Farmer, (Phila.)

We think it is the most complete work upon neat stock that we have seen, embodying as it does a vast amount of research and careful study and observation.-Wisconsin Furmer.

His history of cattle in general, and of the individual breeds in particular which occupies the first one hundred and eighty pares of the volume, is written with much of the grace and charm of an Allison or a Macaulay. His de, scription of the leading breeds is illustrated by cuts of a bull, a cow, and a fat $0 x$, of each race. The next one hundred pages are devoted to the sub. ject of Breeding. This is followed by chapters on Beef Cattle, Working Oxen, Milch Cows. Cattle Food, Diseases, etc. The arrangement, illustrations, analytical index, etc., of the work are in the best style of modern book-mak. ing.-New-England Farmer.

The work is one that has been long needed, as it takes the place of the foreign books of like nature to which our farmers have been obliged to refer, and furnishes in a compact and well-arranged volume all they desire upon this important subject.-Maine Firmer.

Whatever works the stock-farmer may already have, he can not afford to do without this.-Ohio Farmer.

It is one of the best treatises within our knowledge, and contains infor. mation sound and sensible on every page.-The People, (Concord, N. H.)

The object of the work, as stated by the author in his preface, "is not only to give a historical acccount of the Bovine race, to suggest to our farmers and cattle-breeders the best methods of their production and management, but to exalt and ennoble its pursuit to the dignity to which it is entitled in the various departments of American agriculture." From the little examination wo hase been able to give it, we can not recommend it too highly.-Canada. Farmer.

Considering that there are some ten million milch cors in the United States, and nearly a thousand million of dollars invested in cattle, the magni. tude of this interest demands that the best skilled talent be devoted to the improvement of the varions breeds and the investigation of the best method of so caring for the animals as to gain the greatest profit from them. This volume will give the farmer just the instraction which he wants. $-N$. $Y$. Inde pendent.

Price, post-paid, \$2.50.

\section{ORANGE JUDD \& CO.,}

245 Broadway, New-York. 


\section{NEW AMERICAN FARM BOOR.}

ORIGINALIY BY

R. I. A LINI,

ACTHOR OF" "DISEASES OF DOMESTIC ANIRALS," AND FORMERLY IDITOR OF THE "AMERICAY AGRICULTURIST."

REVISED AND EXLARGED BY

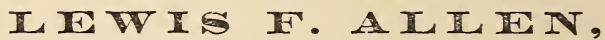

ACTHOR OF "AMTERICAN CATTLE," EDITOR OF THE " AMHERICAN SHORT-HOR HERD воок," Етс.

CONTH NTS:

INTRod -Grazing - Feeding - Breeding Planting, etc.

Chapter I.-Soils - ClassificationDescription - Management - Properties.

Chapter II. - Inorganic ManuresIineral - Stove - Earth - Phosphatic.

Chapter III. - Organic Manures Their Compositiun - Animal-Vegetable.

CHAPTER IV.-Irrigation and Draining.

CHAPter V.-Mechanical Divisions of Soils - Spading - Plowing-Implements.

CHAPTER VI. - The Grasses-Clovers - Headows - Pastures - Comparative Values of Grasses-Implements for their Cultivation.

CaApter YII.-Grain, and its Cultivation - Varieties - Growth-IIarvesting.

Chapter TIII.-Leguminous Plants -Tne Pea-Bean-English Field Bean-Tare or Vetch-Cultivation - Harvesting.

Chapter IX.-Roots and EsculentsVarieties-Growti - Cultivation Securing the Crops-Uses-Nutritive Equivalents of Different Kinds of Foraze.

CHAPter X. - Fruits-Apples-Cider - Vinezar-Pears-Quinces-Plums Pexies - Apricots - Nectarines Smaller Fruits-Planting-Cultiration-Gatherin-Proserving.

Ciapter XI.-Miscellan eous Objects of Cultivation, aside from the $\mathrm{Or}$ dinary Farm Crops-Broom-corilIrlar-Cotton-Hemp-Sugar Cane Sorghum-Maple Surar-TobaccoIndigo-Madder-Wood-SumachTeasel - Mustard - Hops - Castor Bo2n.

CaAPTER XII.-Aids and Objects of Arriculturs - Rotation of Crops, and their Eflects-Weeds-Restora- tion of Worn-out Soils-Fertilizing Barren Lands-Utility of BirdsFences - Hedges - Farm RoadsShade Trees-ivood Lands-Time of Cutting Timber-Tool:-AgTicultural Education of the Farmer.

CHAPTER XIII. - Farm BuildingsHouse - Barn-Sheds - Cisterns Tarious other Outbuildings--Steam. ing Apparatus.

CHAPTER XIV.-Domestic Animals -Breeding-Anatomy-Respiration -Consumption of Food.

Chapter XV.-Neat or Horned Cattle Derons - Herefords-Arreshires Gallowars - Short - horns - Alderneys or Jerseys-Dutch or Holstein. - Management from Birth to Milking, Labor, or Slaughter.

Ceapter XTI.-The Dairy-MilkButter-Cheese-Difierent KindsManner of Working.

CHAPTER XYII. - Sheep - MerinoSaxon-South Down - The Longwooled Breeds-Cotswold-Lincoln - Breeding - BIanagement - Shepherd Dogs.

Cinapter XTIII. - The Horse-Description of Different Breeds-Their Various Uses-Breeding-Management.

Chapter XIX. - The Ass-MinleComparative Labor of Working Animals.

CHAPTER XX. - Smine - Different Breeds - Breeding-Rearing-Fattening-Curing Pork and Hams.

CHAPTER XSI. - Poultry-Hene, or Barn-door Fowls - Turkey - Peacock-Guinea Hen-Goose-Duck - Honey Becs.

CHAPTER XXII. - Diseases of Animals - That Authority Shall We Adopt? - Sheep - Swine - Treatment and Breeding of Horses.

Cirapter XXIII. - Conclusion-Gereral Remarks - The Farmer who Lires by his Occupation-Tha Amateur Farmer-Sundry Useful Tabies.

\section{ORANGE WUDD \& CO.,}




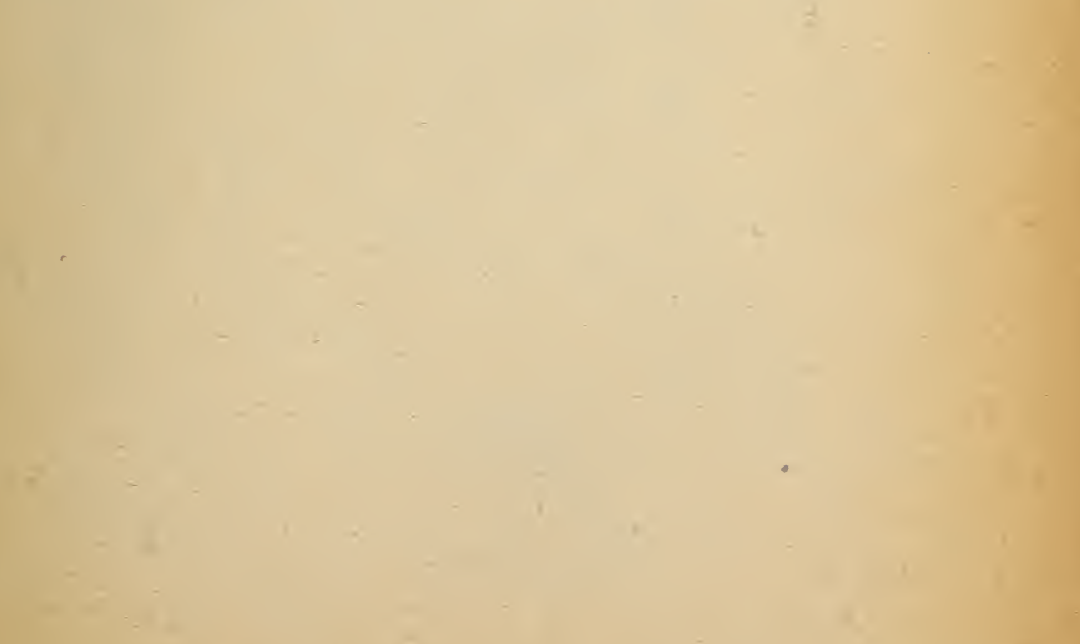

$-4+2=$

(

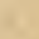


? 


\section{LIBRARY OF CONGRESS}

|||||| || || || || || |||||||||||||||||||||||||||||||||||||

|||||||||||||||||||||||||||||||||||||||||||||||||||||||||||||

00009183978 